\title{
AUTOPRODUCCIÓN DE LOS ÓLEOS ALQUÍDICOS: FORMULACIÓN Y PROPIEDADES
}

\author{
Mariano Espinosa González de San Pedro \\ espinosa_gonzalez@yahoo.es
}

\section{RESUMEN}

Los óleos alquídicos constituyen un tipo de pintura bastante reciente, similares a los óleos tradicionales, pero con un secado más rápido. Precisamente por su relativa novedad no se puede encontrar ningún manual de procedimientos pictóricos en el que se indique cómo un artista puede producir sus propios óleos alquídicos, algo que sí sucede en el caso de los acrílicos y de los óleos tradicionales. El presente trabajo expone una investigación que ha permitido encontrar un aglutinante barato y accesible con el que el artista puede producir sus propios óleos alquídicos. Para ello se ha seleccionado una muestra de resinas alquídicas y se han sometido a diversos análisis de laboratorio y pruebas pictóricas hasta hallar una combinación de resina alquídica y aceite de linaza que se adecúa lo más perfectamente posible al objetivo de la investigación. Una vez encontrado este aglutinante, se ha estudiado en profundidad produciendo pinturas con una amplia gama de pigmentos, y explicando tanto su formulación individual como sus características de cuerpo y viscosidad, brillo, textura, flexibilidad y secado. Finalmente se ha propuesto una paleta con los pigmentos más adecuados para autoproducir óleos alquídicos.

PAlabras Clave: pintura, resinas sintéticas, alquídicos, procedimientos pictóricos, secado.

SELF-PRODUCTION OF ALKYD OILS:

FORMULATION AND PROPERTIES

\section{Abstract}

Alkyd oils are a fairly recent type of paints, similar to traditional oils, yet with a faster drying time. Just because of its relative novelty, no pictorial techniques and materials handbook can be found which could show an artist how to produce their own alkyd oils, which indeed does happen with acrylics or traditional oils. The present study introduces a research that opens doors for an economic and accessible binder by means of which the artist can produce their own alkyd oil paintings. To this end, a wide sample of alkyd resins has been selected and they have been tested through several laboratory analyses and pictorial tests until a combination of alkyd resin and linseed oil, most perfectly suited to the objective of the research, has been found. Once this binder was found, it has been studied in depth by using it to produce paints with a wide range of pigments, and explaining both their individual formulation and their characteristics of Body and viscosity, Gloss, Texture, Flexibility and Drying. Finally, a palette with the most suitable pigments for self-producing alkyd oils has been proposed.

KEYwORDs: painting, synthetic resins, alkyds, painting procedures, drying.

DOI: https://doi.org/10.25145/j.bbaa.2021.15.02

Revista Bellas Artes, 15; diciembre 2021, pp. 33-66; ISSN: e-2530-8432 


\section{INTRODUCCIÓN}

Los óleos alquídicos ocupan un lugar preeminente dentro de los nuevos materiales para la práctica artística que se introdujeron en el mercado de las bellas artes durante el último cuarto del siglo xx, y así lo reconoce, por ejemplo, Max Doerner ${ }^{1}$ (1). Se trata de unas pinturas muy similares a los óleos tradicionales pero con un secado considerablemente más rápido. Esto resulta muy atractivo para los pintores que gustan del acabado brillante y texturado que ofrece el óleo, pero encuentran problemática la lentitud de su secado.

En la actualidad, la única marca que comercializa óleos alquídicos en nuestro país es la británica Winsor \& Newton a través de su línea Griffin alkyd (fast drying oil colour). Pero existen también otras marcas que comercializan óleos alquídicos como la italiana Ferrario alkyd colore alchidico o las norteamericanas CASPaints o DaVinci Paints.

Los objetivos del presente trabajo han sido los siguientes:

1. Encontrar un aglutinante válido para desarrollar óleos alquídicos auto-producidos, teniendo como modelo de referencia los óleos alquídicos Griffin de Winsor \& Newton.

2. Conocer mejor los óleos alquídicos a nivel estructural y práctico.

3. Dar al pintor la opción de auto-producir sus propios óleos alquídicos de forma económica y en las cantidades y con los pigmentos que considere oportunos, si encuentra que las marcas comerciales no satisfacen sus necesidades. Y, de este modo, rellenar un hueco inexplicablemente vacío a día de hoy en los manuales de procedimientos pictóricos.

Aunque todavía no son unas pinturas excesivamente conocidas, lo cierto es que artistas de reconocido prestigio como David Reed, Guillermo Pérez Villalta o Pedro Calapez ${ }^{2}$ trabajan habitualmente o han trabajado en algún momento con óleos alquídicos. Son un tipo de pinturas que se adaptan extraordinariamente bien a sus necesidades. Pero se quejan de su limitada gama de colores y de que, a excepción del blanco de titanio, sólo se vendan en tubos pequeños de $37 \mathrm{ml}$. Esto hace que, para pintar formatos grandes, resulten proporcionalmente unas pinturas caras e incómodas, ya que tienen que exprimir muchos tubos del mismo color para un solo cuadro. Es por esto por lo que alguno de ellos, como Pedro Calapez, ha dejado de trabajar con óleos alquídicos a pesar de que le resultan unas pinturas mucho más

${ }^{1}$ Max Doerner, Los materiales de pintura y su empleo en el arte (Barcelona: Reverté, 2001),

102.

2 Entre 2005 y 2009 el autor mantuvo conversaciones y correspondencia con estos y otros artistas para conocer su relación con los óleos alquídicos. El resultado de las mismas está recogido de forma sintetizada en Mariano Espinosa, «Los alquídicos en la pintura contemporánea». Revista de Bellas Artes 13. (2016): 195-208 (2) https://riull.ull.es/xmlui/bitstream/handle/915/6440/BA_13_\%28201516\%29_09.pdf?sequence=18isAllowed=y (consultado el 15 de diciembre de 2020). 
atractivas que los acrílicos o los óleos tradicionales. De todos modos no dudaría en volver a trabajar con ellos si se solucionasen dichos inconvenientes.

Y, de hecho, la principal motivación del presente trabajo es tratar de aportar soluciones a esta problemática. Si el artista pudiera autoproducirse sus propios óleos alquídicos, del mismo modo que puede autoproducirse sus propios óleos tradicionales siguiendo los consejos de manuales de procedimientos pictóricos tan conocidos como los de Max Doerner ${ }^{3}$, Ralph Mayer ${ }^{4}$ o Antoni Pedrola ${ }^{5}$, los podría producir en las cantidades que deseara y con la cantidad de pigmentos que necesitase, sin estar restringido por la limitada gama de una marca comercial.

\subsection{Metodología}

Tras estudiar los óleos alquídicos industriales Winsor \& Newton Griffin - estudio publicado en Mariano Espinosa ${ }^{6}$ - se pensó que también sería muy útil un trabajo de investigación que posibilitase a los artistas la autoproducción de sus propios óleos alquídicos.

Este trabajo está dividido en dos partes claramente diferenciadas:

La primera parte del trabajo (apartados 1 y 2 ) describe el proceso de búsqueda de un aglutinante que permita la auto-producción de los óleos alquídicos.

Para ello se ha utilizado una muestra de todas las resinas alquídicas formuladas para la pintura artística que se pudieron encontrar en venta al por menor (aquella a la que tiene acceso el artista). La muestra está compuesta por los siguientes productos:

1) Referencia: Griffin blanco de titanio.

2) Kremer 79120. Resina alquídica GG (sin secativo).

3) Alquídico desarrollado en la Universidad de Valencia.

4) Alquídico de Conscolor (tienda de materiales de Barcelona).

5) Kremer 79162 . Laca de resina GG (con secativo).

6) Kremer 79240. Aceite de resina alquídica (medio para pintura).

7) Kremer 79100. Resina alquídica MM (sin secativo).

8) Kremer 79200. Medio para pintar Kremer (secado rápido).

9) Winsor \& Newton Liquin.

10) Talens alkyd médium.

${ }^{3}$ Max Doerner, Los materiales de pintura y su empleo en el arte (Barcelona: Reverté, 2001), 171-175.

${ }^{4}$ Ralph Mayer, Materiales y técnicas del arte (Madrid: H Blume Ediciones, 1993), 208-215.

5 Antoni Pedrola, Materiales y procedimientos pictóricos (Barcelona: Ariel, 1998), 185-186.

${ }^{6}$ Mariano Espinosa, "Los óleos alquídicos Griffin: composición, propiedades y aplicación». Revista de Bellas Artes 11 (2013): 127-157. https://riull.ull.es/xmlui/bitstream/handle/915/2410/ BA_11_\%282013\%29_06.pdf?sequence=5\&is Allowed=y (consultado el 15 de diciembre de 2020). 


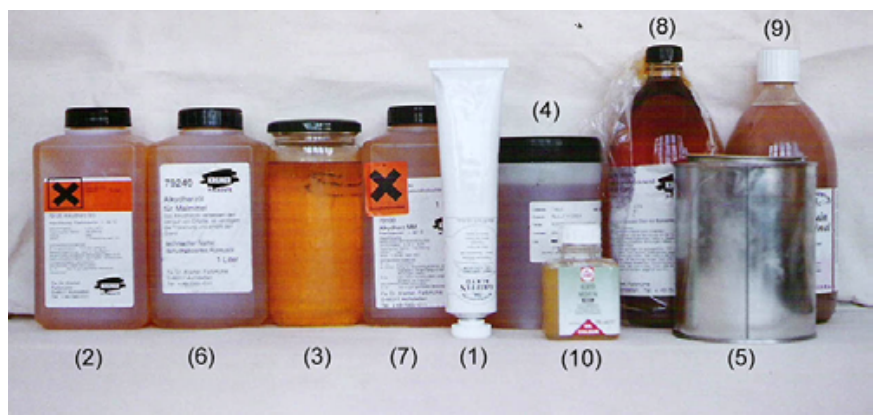

Fig. 1. Muestra de médiums alquídicos seleccionados.

Se trata de diez productos originarios de Alemania, Inglaterra y España y que, por tanto, constituyen una muestra bastante representativa a nivel europeo.

Y estos productos se han sometido a diversos análisis técnicos de laboratorio y pruebas prácticas de ejecución pictórica para comprobar cuál de ellos podría servir como aglutinante, o como base para el aglutinante de unos óleos alquidícos similares a los Griffin de Winsor \& Newton.

Los análisis técnicos se han podido realizar gracias a la inestimable colaboración de la empresa Industrias Químicas Kupsa S.A. y sus químicos Alberto Valencia, Cayetana Landázuri y Aimar Andollo, que ofrecieron su desinteresada colaboración en este trabajo. Dichos análisis, realizados en diferentes fases de la investigación, fueron las siguientes:

a) Prueba comparativa de espectroscopia de infrarrojo: espectroscopia por transmitancia FTIR (Transformada de Fourier) entre $3700-1500 \mathrm{~cm}^{-1}$ realizada con un espectrofotómetro PerkinElmer Spectrum 3 FT- IR spectrometer L1280138. Consiste en comparar cada uno de los productos de la muestra con el producto de referencia. Para ello se utiliza la espectroscopia de infrarrojo y se comparan las gráficas de los espectros de transmitancia de los diferentes productos. Esta técnica de análisis es más cualitativa que cuantitativa. No puede determinar con exactitud la composición de una muestra, pero es indicativa de la semejanza o diferencia entre dos compuestos analizados.

b) Xeno-test: realizado según el protocolo UNE-EN ISO 11507. 2007 con un aparato Qpanel Lab products. Somete los productos a potentes luces infrarrojas y muestra el mayor o menor amarilleamiento del producto con el paso del tiempo. Los resultados de este análisis se han clasificado, de mejor a peor, de la siguiente manera ${ }^{7}$ : 1) no amarillea, 2) amarilleo moderado, 3) amarillea y 4) fuerte amarilleo.

7 La terminología de los resultados de los diversos análisis técnicos es en todo momento la facilitada por el técnico de laboratorio de Industrias Químicas Kupsa S.A. Alberto Valencia. 
c) Cold-check: realizado según el protocolo UNE-EN ISO 48025:1979 con el aparato Dicomental LRT 2V. Consiste en introducir la muestra en una cámara climática, donde se la somete a ciclos alternos de frío y calor. Sirve para observar el grado de deterioro que sufre la película de un producto durante su proceso de envejecimiento dependiendo de las grietas que se hayan formado. Los resultados del Cold-check se han clasificado, de mejor a peor, de la siguiente manera: 1) película no deteriorada, 2) película un poco deteriorada y 3) película bastante deteriorada.

Tanto el Xeno-test como el Cold-check son pruebas de envejecimiento.

d) Cromatografía de gases: realizada con un Hewlett Packard HP 6890 Series bajo los siguientes parámetros: columna: HP-INNOWax (Crosslinked Polyethylene Glycol) inyector: Split $20: 1, \mathrm{~T}=250^{\circ} \mathrm{C}$ gas portador helio $(5 \mathrm{ml} / \mathrm{min})$ horno: $50^{\circ} \mathrm{C}(1 \mathrm{~min}), 10^{\circ} \mathrm{C} / \mathrm{min}$ hasta $220^{\circ} \mathrm{C}$ detector FID, $\mathrm{T}=250^{\circ} \mathrm{C}$. Proporciona información sobre el tipo de disolvente empleado en la fabricación de la resina alquídica. Los diferentes disolventes incluidos en la formulación de una pintura aparecen como picos del cromatograma y su diferente intensidad será indicativa de su concentración.

e) Prueba de sólidos: realizada según el protocolo UNE-EN ISO 3251:2008 con una estufa tipo mufla de Heraues Instruments. Indica el porcentaje de contenidos sólidos de una muestra y, por defecto, también el de contenidos no sólidos, que suelen ser los disolventes. Funciona aplicando calor a la muestra hasta que se evaporan todos los contenidos no sólidos. Como complemento a la prueba de sólidos, se ha averiguado el porcentaje de pigmento. Para ello se introduce la pintura en una centrifugadora que separa por un lado el pigmento con algún resto de aglutinante y por otro el disolvente y casi todo el aglutinante. Después, se toma el espectrograma del total y, conociendo dicho espectrograma y la cantidad aproximada de pigmento, se calcula el porcentaje final de pigmento. De este modo se puede averiguar el porcentaje exacto de cada uno de los componentes principales de cada pintura: aglutinante, pigmento y disolvente.

Después, las pruebas prácticas han consistido en producir pinturas aglutinando varios pigmentos con las distintas resinas alquídicas y mezclas de resina alquídica con aceite de linaza que se han estudiado, y pintar una serie de lienzos con ellas. Para así poder comprobar no sólo a través de la composición química, sino también a través de sus propiedades físicas y pictóricas, con qué aglutinante se pueden producir unos óleos alquidicos más similares al modelo de referencia Winsor \& Newton Griffin.

Las variables estudiadas en esta fase han sido las siguientes:

Cuerpo y viscosidad: lo ideal es que la pintura salga del tubo con la viscosidad de una crema. Cuanto más cuerpo tenga el óleo alquídico autoproducido más parecido será a nuestro modelo de referencia. Los resultados de esta variable se han clasificado, de mejor a peor, de la siguiente manera: 1) cremosa, 2) poco viscosa y 3) semilíquida. 
Textura y empaste: lo idóneo es que los óleos alquídicos, al igual que los óleos tradicionales, permitan realizar empastes y crear texturas, puesto que no son pinturas planas. Los resultados de textura y empaste se han clasificado, de mejor a peor, de la siguiente manera: 1) pinturas que permiten realizar texturas, 2) pinturas semiplanas y 3 ) pinturas planas.

Brillo: los óleos alquídicos no tienen tanto brillo como el óleo tradicional, pero distan mucho de ser mates. Lo mejor es que sean brillantes, por eso sus resultados en esta variable se han clasificado, de mejor a peor, de la siguiente manera: 1) brillante, 2) satinada y 3) mate.

Flexibilidad: las pinturas son flexibles cuando se doblan, en lugar de quebrarse, si una fuerza actúa sobre ellas; y recobran su estado primitivo cuando esta deja de actuar. Los resultados de flexibilidad se han clasificado, de mejor a peor, de la siguiente manera: 1) muy flexible, 2) flexible, 3) poco flexible y 4) muy poco flexible.

Separación de aglutinante y pigmento: cuando las pinturas autoproducidas se almacenan durante bastante tiempo se pueden producir este tipo de separaciones, quedando la pintura como una masa dura dentro del tubo si hay demasiada separación. Los resultados de esta variable se han clasificado, de mejor a peor, de la siguiente manera: 1) no hay separación de aglutinante y pigmento, 2) hay un poco de separación de aglutinante y pigmento y 3 ) hay mucha separación de aglutinante y pigmento.

Margen de secado: tiempo durante el cual se puede trabajar con la pintura en la paleta antes de que seque de tal manera que ya no se pueda manejar con el pincel. Sus resultados se han clasificado, de mejor a peor, de la siguiente manera: 1 ) gran margen de secado - más de $12 \mathrm{~h}-$, 2) amplio margen de secado -entre 4 y $12 \mathrm{~h}-$, 3) suficiente margen de secado -entre 1 y $4 \mathrm{~h}-4$ ) poco margen de secado - menos de $1 \mathrm{~h}^{-}{ }^{8}$.

Finalmente, en la segunda parte del trabajo (apartado 3), tras seleccionar el aglutinante más adecuado para la autoproducción de óleos alquídicos, se ha utilizado dicho aglutinante para producir toda una serie de colores con una gama de 28 pigmentos (suministrados por Conscolor Bellas Artes SL). Y se ha estudiado la reacción de cada pigmento con dicho aglutinante observando la cantidad de aglu-

${ }^{8}$ Por cuestión de espacio no se puede ofrecer aquí una definición más detallada de los resultados de las diferentes variables. Quien requiera más precisión tiene todos los términos definidos de manera precisa en Mariano Espinosa, Tesis doctoral Las resinas alquidicas aplicadas a la pintura artística (Barcelona: Universitat de Barcelona: Departament de pintura, 2010), 36-44. (8) De todos modos se acordó con el director de la tesis, José Francisco García Martínez, del Departamento de Ingeniería Química y Química Analítica de la Universidad de Barcelona, emplear unos términos más orientados a los artistas-pintores a los que iba dirigida la tesis que a los químicos. Es por esto por lo que en este artículo sólo se ha considerado necesaria una mayor precisión en la variable margen de secado, al ser la que pudiera resultar más ambigua y confusa para el lector del artículo. 
tinante que necesita, las vicisitudes de su autoproducción y su mayor o menor parecido con el modelo de referencia Griffin, entre otras variables.

Los 28 pigmentos que se han empleado en este trabajo son los siguientes:

blanco de plomo $2 \mathrm{PbCO}^{3} \cdot \mathrm{Pb}(\mathrm{OH})^{2}$, blanco titanio $\mathrm{TiO}^{2}$, blanco de zinc $\mathrm{ZnO}$, amarillo cadmio CdSd, amarillo Hansa $\mathrm{C}^{7} \mathrm{H}^{16} \mathrm{~N}^{4} \mathrm{O}^{4}$, amarillo cromo $\mathrm{PbCrO}$, amarillo Nápoles $\mathrm{Pb}\left(\mathrm{SbO}^{3}\right) \cdot 9 \mathrm{H}^{2} \mathrm{O}$, ocre amarillo $\mathrm{Fe}^{2} \mathrm{O}^{3} \cdot \mathrm{H}^{2} \mathrm{O}$, rojo cadmio $\mathrm{CdS}(\mathrm{Se})$, rojo naftol $\mathrm{C}^{24} \mathrm{H}^{16} \mathrm{C}^{13} \mathrm{~N}^{3} \mathrm{O}^{2}$, carmín de alizarina $\mathrm{C}^{14} \mathrm{H}^{8} \mathrm{O}^{4}$, rojo de óxido de hierro $\mathrm{Fe}^{2} \mathrm{O}^{3}$ (PR101), ocre rojo $\mathrm{Fe}^{2} \mathrm{O}^{3}$ (PR102), violeta de manganeso $\mathrm{H}^{4} \mathrm{O}^{7} \mathrm{P}^{2} \cdot \mathrm{H}^{3} \mathrm{~N} \cdot \mathrm{Mn}$, azul cobalto $\mathrm{CoO} \cdot \mathrm{Al}^{2} \mathrm{O}^{3}$, azul ultramar $10 \mathrm{~S}^{2} \mathrm{Al}^{6} \mathrm{Si}+\mathrm{O}^{20} \cdot 8 \mathrm{Na}$, azul de Prusia $\mathrm{C}^{6} \mathrm{FeN}^{6} \cdot \mathrm{H}^{4} \mathrm{~N}$, azul de ftalocianina $\mathrm{C}^{32} \mathrm{H}^{16} \mathrm{CuN}^{8}$, azul cerúleo $\mathrm{CoO} \cdot \mathrm{nSnO}^{2}$, verde de óxido de cromo $\mathrm{Cr}^{2} \mathrm{O}^{3}$, verde de ftalocianina $\mathrm{C}^{32} \mathrm{H}^{16} \mathrm{CuN}^{8} \mathrm{Cl}^{15}$, siena natural $\mathrm{Fe}^{2} \mathrm{O}^{3}(\mathrm{PBr} 7)$, siena tostada $\mathrm{Fe}^{2} \mathrm{O}^{3}$ calcinado( $\left.\mathrm{PBr} 7\right)$, sombra natural $\mathrm{Fe}^{2} \mathrm{O}^{3} \cdot \mathrm{MnO} 2$, sombra tostada $\mathrm{Fe}^{2} \mathrm{O}^{3} \cdot \mathrm{MnO}^{2}$ calcinado, negro marfil $\mathrm{C}+\mathrm{Ca}\left(\mathrm{PO}^{4}\right)^{2}$, negro de hierro $\mathrm{Fe}^{3} \mathrm{O}^{4}$ y negro humo $\mathrm{C}$.

Antes de aglutinar los pigmentos siempre se los ha mezclado en proporción $75 \% / 25 \%$ con una carga de hidrato de alúmina $\left(\mathrm{Al}^{2} \mathrm{O}^{3}\right)$ marca Conscolor. Esta es la carga que recomiendan tanto Max Doerner ${ }^{9}$ como Antoni Pedrola ${ }^{10}$ para dar cuerpo y cremosidad a los colores al óleo.

El aceite de linaza que se ha utilizado ha sido aceite de linaza prensado en frío marca Conscolor. Para los pigmentos blancos se ha usado aceite de adormideras Talens, porque amarillea menos que el de linaza.

Para concluir conviene señalar también que las pruebas prácticas se han trabajado sobre tela de algodón imprimada a la creta y los estudios del secado de las pinturas sobre tela de lino imprimada tanto a la creta como a la media creta ${ }^{11}$.

\section{EL AGLUTINANTE PARA ÓLEOS ALQUÍDICOS AUTOPRODUCIDOS}

El elemento principal para poder formular cualquier tipo de pinturas es el aglutinante. Por lo tanto, el principal paso que hay que dar para poder autoproducir óleos alquídicos caseros tipo Griffin es averiguar cuál es el aglutinante de los óleos alquídicos $W \& N$ Griffin o, al menos, encontrar uno lo más similar posible,

173.

9 Max Doerner, Los materiales de pintura y su empleo en el arte (Barcelona: Reverté, 2001),

${ }_{10}$ Antoni Pedrola, Materiales y procedimientos pictóricos (Barcelona: Ariel, 1998), 86.

${ }^{11}$ Para quien desconozca estos términos: imprimación de creta: Aquella en la que tras aplicar al soporte una capa de cola de conejo diluida en agua se procede a aplicar varias capas de la mezcla de 1 volumen de creta o de blanco de España, 1 volumen de blanco de zinc o de litopón y 2 volúmenes de cola de conejo hinchada en agua. Imprimación de media creta: tras la capa inicial de aguacola se aplican capas sucesivas de la mezcla de 1 volumen de creta o blanco de España, 1 volumen de blanco de zinc o litopón, 1 o 2 volúmenes de cola de conejo hinchada en agua y entre $1 / 3$ y $2 / 3$ de volumen de stand oil o resina alquídica. 


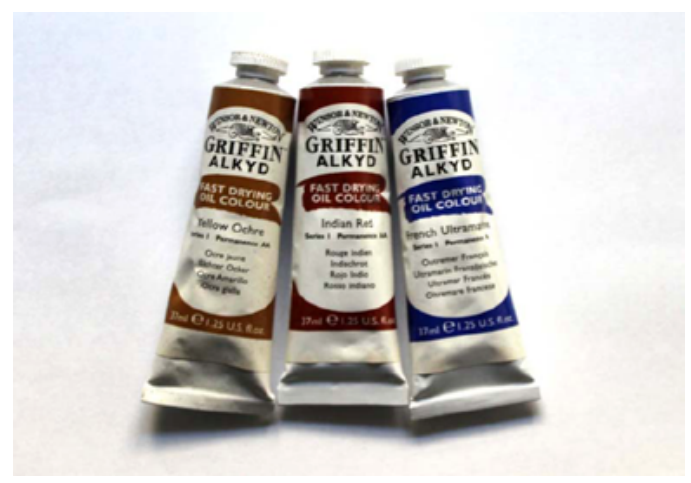

Fig. 2. Óleos alquídicos Griffin.

y que sea accesible para cualquier artista. Para ello, conviene que conozcamos primero bien las cualidades de los óleos alquídicos Griffin, puesto que son las que han de compartir los óleos alquídicos autoproducidos.

\subsection{Cualidades de los óleos alquídicos GRIFFin}

Atendiendo a las variables enumeradas en 0.1., las propiedades de los óleos alquídicos fabricados industrialmente son las siguientes ${ }^{12}$ :

Margen de secado: su margen de secado es de entre 12 y 24 horas. El margen varía de un color a otro pero todos han secado en 24 horas. Lo que hace que sequen al menos el triple de rápido que los óleos tradicionales.

Cuerpo y viscosidad: son unas pinturas cremosas, aunque con una consistencia ligeramente menos viscosa que los óleos tradicionales. Su manejabilidad es óptima y no difiere nada de la de estos últimos.

Textura y empaste: poseen una gran plasticidad y también una gran capacidad para crear empastes. Pueden crear la misma variedad de texturas que los óleos tradicionales. Pero sus empastes son un poco menos voluminosos, pues tienden a encogerse durante el secado.

Brillo: son unas pinturas brillantes, aunque un poco menos que los óleos tradicionales. Al secar la pintura pierde un poco de brillo, y en capas finas es más bien

12 Todas las cualidades aquí señaladas fueron estudiadas y recogidas en mi artículo Mariano Espinosa, «Los óleos alquídicos Griffin: composición, propiedades y aplicación». Revista de Bellas Artes 11 (2013): 127-157. https://riull.ull.es/xmlui/bitstream/handle/915/2410/ BA_11_\%282013\%29_06.pdf?sequence=58 $\overline{\text { isAllowed }=y}$ (consultado el 15 de diciembre de 2020). 
una pintura satinada, que se va volviendo cada vez más brillante a medida que aumenta el grosor de la capa.

Flexibilidad: se trata de unas pinturas flexibles. Algo más que los óleos tradicionales pero menos que los acrílicos. Es cierto que, al igual que los óleos, con el paso del tiempo tienden a perder flexibilidad y volverse más quebradizos, aunque no tanto como aquellos. La flexibilidad de un óleo alquídico varía dependiendo del pigmento con el que se ha fabricado. Hay pigmentos como el blanco de plomo, el amarillo Nápoles o el azul cerúleo que producen pinturas menos flexibles.

Separación de aglutinante y pigmento: apenas muestran este tipo de separaciones.

Por lo general, al abrir un tubo se puede observar simplemente un rastro húmedo de aglutinante en la superficie de la pintura, que a veces forma una gota. Aunque también hay algún pigmento más problemático como el azul cerúleo y el negro humo.

Envejecimiento: esta variable ha sido estudiada tanto por el equipo de Ploeger, Rebecca 2008, p. $415^{13}$ como por Mecklenburg, Marion $2007^{14}$, y ambos coinciden en que su proceso de envejecimiento es similar al de los óleos tradicionales. El segundo incluso asevera que los óleos alquídicos muestran una menor pérdida de flexibilidad con el tiempo. Durante los análisis técnicos se ha observado una gran estabilidad en sus películas (Cold-check) y un prácticamente nulo amarilleo (Xeno-test), salvo en el caso de los blancos, que sí muestran un ligero amarilleo.

Estas son, a grandes rasgos, las cualidades que el aglutinante buscado ha de otorgar a los óleos alquídicos autoproducidos. Siempre teniendo en cuenta que las pinturas autoproducidas no pueden ser $100 \%$ iguales a las fabricadas industrialmente. En las pinturas industriales cada color tiene una compleja fórmula química individual y secreta, que muchas veces incluye componentes que no son fácilmente accesibles al por menor. Además, están amasadas con unas máquinas que permiten emplear menos aceite y mezclarlo más perfectamente con el pigmento que el amasado manual con moleta. Es por ello por lo que, por ejemplo, los óleos tradicionales autoproducidos, comparados con los fabricados industrialmente, son menos brillantes, menos flexibles, amarillean algo más y muestran mayor separación de aglutinante y pigmento. Pero eso no quiere decir que no sean perfectamente válidos para la práctica pictórica (los óleos auto-producidos ya existían antes que los modernos procesos de fabricación industrial), simplemente es un detalle a tener en cuenta.

13 Ploeger, Rebecca, Scalarone, Dominique y Chiantore, Oscar. "Characterization of commercial artists' alkyd paints». Journal of Cultural Heritage 9. (2008): 412-419.

14 Meklenburg, Marion. «Determining the aceptable ranges of relative humidity and temperatura in Museums and Galleries. Part 2, Structural Response to Temperature». Smithsonian Museum Conservation Institute (2007). http://www.si.edu/mci/downloads/reports/MecklenburgPart2-Temp.pdf. (consultado el 21-3-2009). 


\begin{tabular}{|c|c|c|c|}
\hline \multicolumn{4}{|c|}{ TABLA I. RESULTADOS DE LAS PRUEBAS TÉCNICAS } \\
\hline Producto & Prueba COMParativa & XENO-TEST & COLD-CHECK \\
\hline $\begin{array}{l}\text { W\&N Griffin } \\
\text { blanco titanio }\end{array}$ & & Amarillea & Película poco deteriorada \\
\hline Kremer 79120 & $\begin{array}{l}\text { Su composición no se aproxima } \\
\text { demasiado a la del } W \mho N \text { Griffin }\end{array}$ & Amarilleo moderado & $\begin{array}{l}\text { La película } \\
\text { no se ha deteriorado }\end{array}$ \\
\hline $\begin{array}{l}\text { Alquídico Universi- } \\
\text { dad de Valencia }\end{array}$ & $\begin{array}{l}\text { No se parece mucho al agluti- } \\
\text { nante de los W\&N Griffin }\end{array}$ & $\begin{array}{l}\text { Amarilleo moderado } \\
\text { (casi no amarillea) }\end{array}$ & Película poco deteriorada \\
\hline Alquídico Conscolor & No se parece a $W \circlearrowleft N$ Griffin & Amarilleo moderado & $\begin{array}{l}\text { Película bastante } \\
\text { deteriorada }\end{array}$ \\
\hline Kremer 79162 & $\begin{array}{l}\text { Se puede considerar que guarda } \\
\text { una cierta similitud con el } \\
W \mho N \text { Griffin }\end{array}$ & Amarilleo moderado & $\begin{array}{l}\text { La película } \\
\text { no se ha deteriorado }\end{array}$ \\
\hline Kremer 79240 & $\begin{array}{l}\text { No tiene nada que ver con los } \\
W \& N \text { Griffin }\end{array}$ & Fuerte amarilleo & $\begin{array}{l}\text { Película bastante } \\
\text { deteriorada }\end{array}$ \\
\hline Kremer 79100 & $\begin{array}{l}\text { No guarda mucho parecido con } \\
\text { el aglutinante de } W \mho N \text { Griffin }\end{array}$ & Amarilleo moderado & $\begin{array}{l}\text { Película bastante } \\
\text { deteriorada }\end{array}$ \\
\hline Kremer 79200 & $\begin{array}{l}\text { Es muy distinto del } \\
W \mho N \text { Griffin }\end{array}$ & $\begin{array}{l}\text { Fuerte amarilleo. La } \\
\text { pintura se desconcha }\end{array}$ & $\begin{array}{l}\text { Película bastante } \\
\text { deteriorada }\end{array}$ \\
\hline $\begin{array}{l}\text { Winsor \& Newton } \\
\text { Liquin }\end{array}$ & $\begin{array}{l}\text { Tiene casi el mismo espectro } \\
\text { que la muestra de W\&NGriffin. } \\
\text { En este apartado es el mejor sin } \\
\text { duda }\end{array}$ & No amarillea & Película poco deteriorada \\
\hline $\begin{array}{l}\text { Talens alkyd } \\
\text { médium }\end{array}$ & $\begin{array}{l}\text { No es muy parecido } \\
\text { al aglutinante de las pinturas } \\
W \mathcal{O} N \text { Griffin }\end{array}$ & Amarilleo & $\begin{array}{l}\text { La película } \\
\text { no se ha deteriorado }\end{array}$ \\
\hline
\end{tabular}

\subsection{ANÁlisis TÉCNICOS}

Para averiguar cuál de los productos alquídicos de la muestra seleccionada es el aglutinante más parecido al de los óleos alquídicos Griffin (o, al menos, para ir descartando los menos similares) se los ha sometido a todos a diversos análisis técnicos. El primero, la prueba comparativa de espectroscopia de infrarrojo. Y después también al Xeno-test y Cold-check, para disponer de más datos.

Los resultados de estas pruebas están resumidos ${ }^{15}$ (8) en la tabla I.

En la prueba comparativa los mejores resultados los han obtenido el Winsor \& Newton Liquin y el Kremer 79162.

15 Esta tabla es un resumen de los resultados. Si se quieren ver en detalle, con las gráficas de las pruebas comparativas y fotos del resultado de las pruebas de envejecimiento, se pueden consultar en Mariano Espinosa, Tesis doctoral Las resinas alquidicas aplicadas a la pintura artística (Barcelona: Universitat de Barcelona: Departament de pintura, 2010), 252-256 (8). 


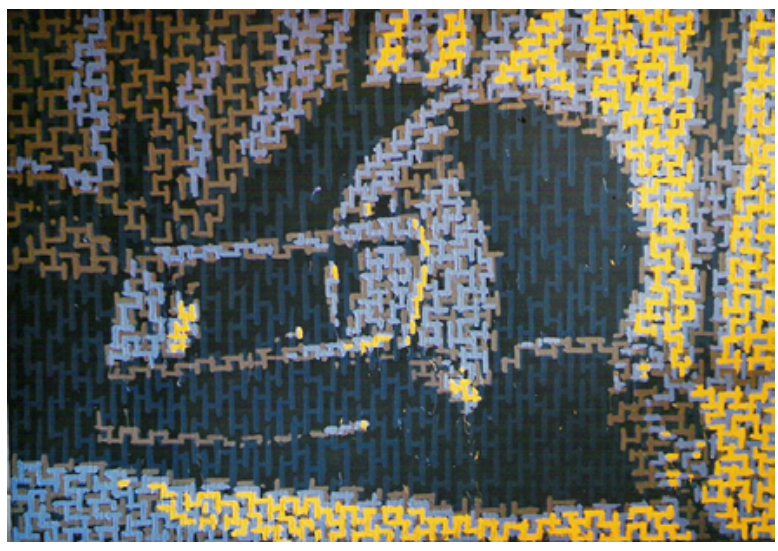

Fig. 3. Naturaleza muerta v. Alquídico Liquin sobre algodón. $89 \times 130 \mathrm{~cm}$.

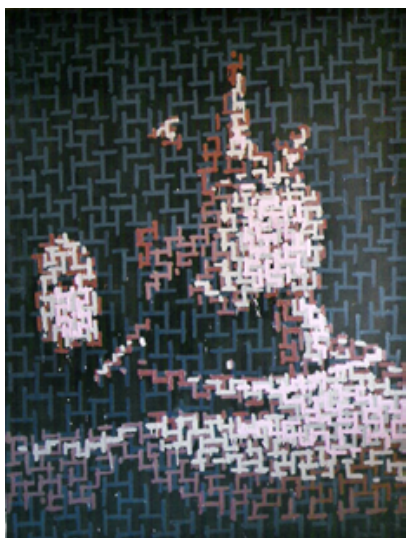

Fig. 4. Naturaleza muerta VI. Alquídico Kremer 79162 sobre algodón. $130 \times 97 \mathrm{~cm}$.

En el Xeno-test los mejores resultados han sido los del Windsor \& Newton Liquin y el alquídico de la Universidad de Valencia. Y, en menor medida, el Kremer 79162, el Kremer 79120 y el alquídico de Conscolor.

En el Cold-check los mejores resultados los han obtenido el Kremer 79162, el Kremer 79120 y el alquídico Talens. Y, en menor medida, el Winsor \& Newton Liquin y el alquídico de la Universidad de Valencia.

En resumen, los productos más similares al aglutinante de los óleos alquídicos WeN Griffin han sido el Liquin de Winsor \& Newton y el Kremer 79162. Son, con diferencia, los más parecidos según la prueba comparativa (especialmente el Liquin) y, además, han obtenido buenos resultados tanto en el Xeno-test como en el Coldcheck (Liquin mejor en el Xeno-test y Kremer 79162 en el Coldcheck).

Por tanto, estos dos son los productos seleccionados para continuar con las pruebas prácticas, descartando los demás.

\subsection{Pruebas prácticas}

El objetivo de estas pruebas ha sido ayudar a decidir cuál de los dos aglutinantes seleccionados en los análisis técnicos, Winsor \& Newton Liquin o Kremer 79162, es la mejor opción para aglutinar pinturas que tengan las mismas características que los alquídicos W\& $N$ Griffin. Para ello se han producido pinturas aglutinando con estos dos productos una muestra de siete colores -blanco de titanio, amarillo Hansa, rojo naftol, azul ultramar, ocre amarillo, ocre rojo y negro marfil-. Se aglutinan de la siguiente manera: de cada pigmento se han pesado $100 \mathrm{gr}$, a los que se han ańadido $33 \mathrm{~g}$ de hidrato de alúmina como carga. Se ha hecho un montoncito con ello y, sobre él, se ha vertido poco a poco resina alquídica y se han 


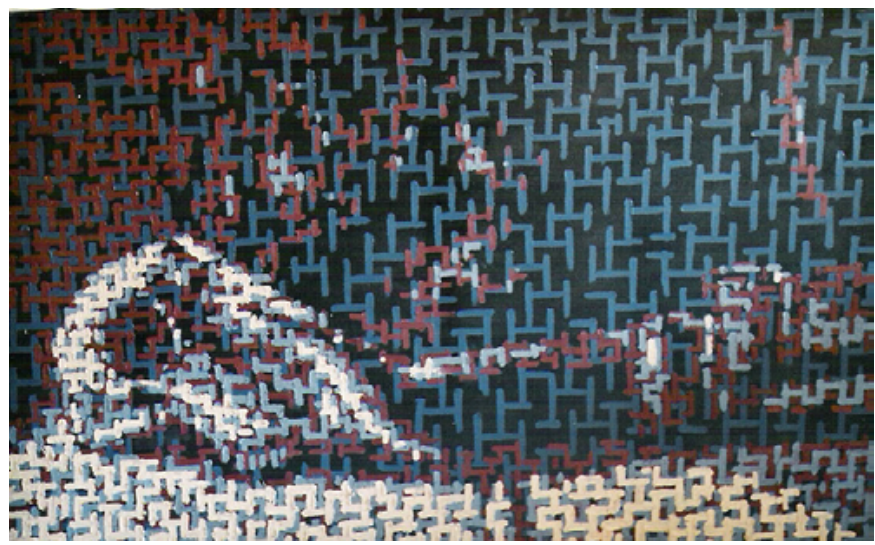

Fig. 5. Vánitas VIII. Alquídico Griffin sobre algodón. $81 \times 130 \mathrm{~cm}$.

amasado la resina, la carga y el pigmento con una espátula tipo rasqueta hasta que todo ha quedado aglutinado. En estas pinturas basta un amasado enérgico de espátula, no es necesario un segundo amasado con moleta. Después se han pintado con ellas varios lienzos, en diferentes estilos (figs. 3-5) ${ }^{16}$. También se han pintado varios cuadros con los óleos alquídicos Griffin (fig. 5), para poder comparar los resultados. observaciones:

A partir de las variables estudiadas se han podido realizar las siguientes

Pinturas aglutinadas con Winsor \& Newton Liquin.

1. Su viscosidad no es uniforme, algunos pigmentos proporcionan pinturas cremosas, mientras que otros producen pinturas poco viscosas o semilíquidas.

2. No pueden conseguir texturas, pero sí empastes. El problema es que estos empastes son muy frágiles y tienden a craquelarse.

3. Pierden brillo al secar y quedan satinadas, con zonas incluso mate.

4. No son muy flexibles, es mejor emplearlas para pintar sobre soportes rígidos.

5. Su principal problema es que, pasado un tiempo, pigmento y aglutinante tienden a separarse. En muchos casos, al abrir el tubo y apretarlo para depositar la pintura sobre la paleta, sale un molesto y gran chorro de aglutinante (fig. 6). También puede ocurrir que la pintura que se encuentra en la parte

16 Por motivos de espacio se muestra aquí un sólo un cuadro de cada aglutinante. El resto, pintados en diferentes estilos se pueden consultar en Mariano Espinosa, Tesis doctoral Las resinas alquidicas aplicadas a la pintura artística (Barcelona: Universitat de Barcelona: Departament de pintura, 2010), 267-293 (8). 


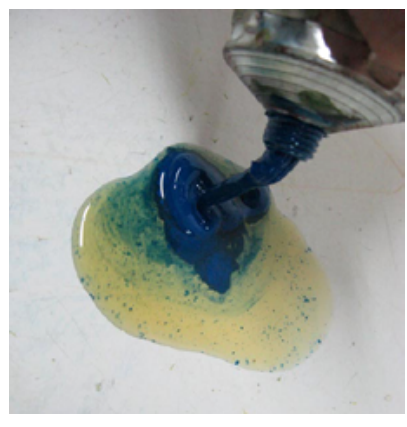

Fig. 6.

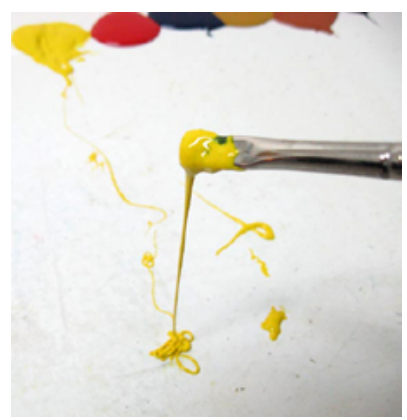

Fig. 7.

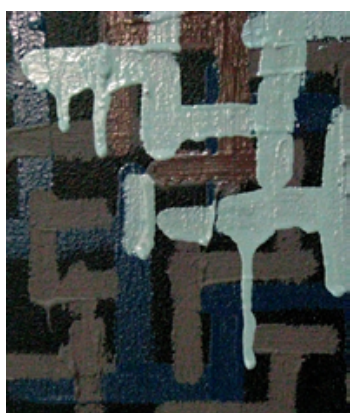

Fig. 8.

inferior del tubo se endurezca como un plástico duro y quede inutilizable para pintar. Hay que señalar que esto no sucede con los pigmentos de granulometría menor (Hansa, naftol etc.)

6. Tienen un amplio margen de secado que permite pintar con relativa facilidad.

Pinturas aglutinadas con Kremer 79162.

1. Consigue unas pinturas poco viscosas (fig. 7), lo que hace que sea incómodo pintar con ellas en soportes verticales (fig. 8), si bien sobre superficies apoyadas en posición horizontal resulta menos problemático.

2. Esta falta de viscosidad no sólo contribuye a que su manejo sea más incómodo, sino que también imposibilita la consecución de texturas o empastes.

3. Son muy brillantes, de un brillo parecido al de los esmaltes, mucho más brillantes que los óleos tradicionales y que los óleos alquídicos Wén $N$ Griffin.

4. Son unas pinturas poco flexibles.

5. La separación entre pigmento y aceite no es tan importante como la detectada en el $W \mho N$ Liquin, por lo que las pinturas se pueden almacenar durante más tiempo sin que se produzca este desagradable efecto.

6. Su principal problema es su escaso margen de secado. Hay que pintar muy rápido, porque en hora y media los colores de la paleta están ya semisecos y comienza a resultar complicado trabajar con ellos, ya que casi no se pueden arrastrar y cuesta mezclarlos.

La tabla II muestra un resumen de estas observaciones (ver página siguiente).

En resumen, tanto las pinturas aglutinadas con Winsor \& Newton Liquin como las aglutinadas con Kremer 79162 son inferiores en casi todas las variables a las pinturas W\&N Griffin-la excepción es el brillo en el caso de Kremer 79162-. Por tanto, no son viables como óleos alquídicos autoproducidos y hay que continuar buscando la formulación adecuada. 


\begin{tabular}{|c|c|c|c|c|c|c|}
\hline \multicolumn{7}{|c|}{ TABLA II. RESULTADOS DE LAS PRUEBAS PRÁCTICAS } \\
\hline 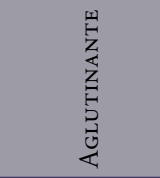 & 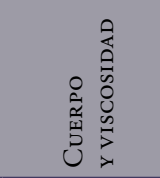 & 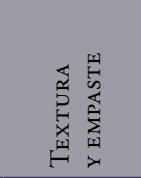 & 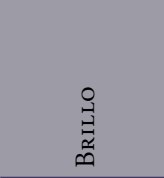 & 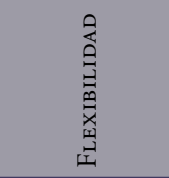 & 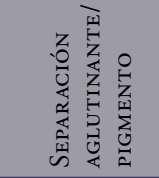 & 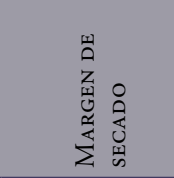 \\
\hline $\begin{array}{l}\text { Referencia: } \\
\text { W\&N Griffin } \\
\text { (fig. 4) }\end{array}$ & Cremosas & $\begin{array}{l}\text { Permiten } \\
\text { realizar } \\
\text { texturas }\end{array}$ & $\begin{array}{l}\text { Brillantes } \\
\text { (pero menos } \\
\text { que el óleo) }\end{array}$ & Muy flexibles & $\begin{array}{l}\text { No hay } \\
\text { separación de } \\
\text { aglutinante }\end{array}$ & $\begin{array}{l}\text { Amplio margen } \\
\text { de secado } \\
(12-24 \mathrm{~h})\end{array}$ \\
\hline $\begin{array}{l}W \mho N \text { Liquin } \\
\text { (fig. 2) }\end{array}$ & Poco viscosas & Semiplanas & Satinadas & $\begin{array}{l}\text { Entre poco } \\
\text { flexibles y muy } \\
\text { poco flexibles }\end{array}$ & $\begin{array}{l}\text { Hay mucha } \\
\text { separación de } \\
\text { aglutinante }\end{array}$ & $\begin{array}{l}\text { Suficiente mar- } \\
\text { gen de secado } \\
(6-8 \mathrm{~h})\end{array}$ \\
\hline $\begin{array}{l}\text { Kremer } 79162 \\
\text { (fig. 3) }\end{array}$ & $\begin{array}{l}\text { Entre poco } \\
\text { viscosas y } \\
\text { semilíquidas }\end{array}$ & Planas & $\begin{array}{l}\text { Brillantes } \\
\text { (y esmaltadas) }\end{array}$ & Poco flexibles & $\begin{array}{l}\text { No hay } \\
\text { separación de } \\
\text { aglutinante }\end{array}$ & $\begin{array}{l}\text { Poco margen } \\
\text { de secado } \\
(1,5 \mathrm{~h})\end{array}$ \\
\hline
\end{tabular}

\section{PINTURAS AGLUTINADAS CON RESINA ALQUÍDICA Y ACEITE DE LINAZA MEZCLADOS EN DISTINTAS PROPORCIONES}

La primera hipótesis con la que se ha trabajado en esta nueva fase de búsqueda $-\mathrm{y}$ que luego ha demostrado ser la correcta- fue que, ya que los productos alquídicos destinados a la práctica artística siempre están formulados con resinas alquídicas largas de aceite, probablemente los óleos alquídicos W\& $N$ Griffin estaban aglutinados con un médium alquídico aún más largo de aceite que el Winsor \& Newton Liquin o el Kremer 79162.

Otros motivos que llevaron a plantear esta hipótesis fueron los siguientes:

1. El aceite puede retardar un poco el secado excesivamente rápido de estas resinas alquídicas, que secan bastante más rápido que los óleos alquídicos $W \mho N N$ Griffin.

2. Es posible que el aceite pueda contribuir también a mejorar la viscosidad y reducir la fluidez de las pinturas, y es prácticamente seguro que mejorará su capacidad para crear texturas y empastes.

3. Puede contribuir también a mejorar el brillo en el caso de las pinturas aglutinadas con W\&N Liquin.

4. Por último, podría mejorar a su vez la flexibilidad de las pinturas.

Así pues, el siguiente paso consistió en mezclar, en diferentes proporciones, medio alquídico y aceite de linaza y comprobar los resultados de las pinturas aglutinadas con estas mezclas hasta ver cuál de ellas obtenía unos resultados más similares a los de los óleos alquídicos WéN Griffin.

Las proporciones en que las dos resinas alquídicas seleccionadas se mezclaron con aceite de linaza fueron las siguientes: 
a) $75 \%$ resina alquídica $-25 \%$ aceite de linaza

b) $50 \%$ resina alquídica $-50 \%$ aceite de linaza

c) $25 \%$ resina alquídica $-75 \%$ aceite de linaza

La mezcla se realizó vertiendo en un recipiente la cantidad proporcional en gramos de resina alquídica primero y de aceite de linaza después, removiendo todo con una varilla.

Finalmente, con cada mezcla se han aglutinado $100 \mathrm{~g}$ de pigmento negro marfil $+33 \mathrm{~g}$ de hidrato de alúmina. Así pues, la muestra definitiva con la que se ha trabajado ha sido la siguiente:

1) Referencia: alquídico Griffin negro marfil.

2) Negro marfil aglutinado con $75 \%$ W $\diamond N$ Liquin- $25 \%$ aceite de linaza.

3) Negro marfil aglutinado con $50 \% W \mho N$ Liquin- $50 \%$ aceite de linaza.

4) Negro marfil aglutinado con $25 \% W \mho N N$ Liquin- $75 \%$ aceite de linaza.

5) Negro marfil aglutinado con $75 \%$ Kremer $79162-25 \%$ aceite de linaza.

6) Negro marfil aglutinado con $50 \%$ Kremer $79162-50 \%$ aceite de linaza.

7) Negro marfil aglutinado con $25 \%$ Kremer $79162-75 \%$ aceite de linaza.

Y, nuevamente, con estas muestras se han realizado tanto análisis técnicos como pruebas prácticas, para ver si alguno de estos aglutinantes nos puede proporcionar unas pinturas equivalentes a los óleos alquídicos WeN Griffin.

\subsection{ANÁLISIS TÉCNICOS}

Los análisis técnicos que se aplicaron a estas muestras fueron los siguientes: prueba comparativa mediante espectroscopia de infrarrojo, cromatografía de gases y prueba de sólidos ${ }^{17}$ :

La prueba comparativa dio como resultado que la muestra que tiene una composición más similar a la de los óleos alquídicos WéN Griffin es la de la pintura aglutinada con 25\% We $N$ Liquin-75\% aceite de linaza. La segunda más parecida es la de la pintura aglutinada con 25\% Kremer 79162-75\% aceite de linaza. Lo que parece confirmar la hipótesis de que el problema

${ }_{17}$ Los resultados de los análisis técnicos aquí expuestos son una síntesis muy concisa de los mismos. Los resultados completos, incluyendo las gráficas de la prueba comparativa y las de la cromatografía de gases, se pueden consultar en Mariano Espinosa. Tesis doctoral Las resinas alquidicas aplicadas a la pintura artística (Barcelona: Universitat de Barcelona: Departament de pintura, 2010), 368-371 (8). 


\begin{tabular}{|c|c|c|c|c|}
\hline $\begin{array}{c}\text { PINTURAS } \\
\text { (TODAS ELLAS NEGRO MARFIL) }\end{array}$ & $\begin{array}{c}\% \text { SÓLIDOS = } \\
\text { PIGMENTO + } \\
\text { AGLUTINANTE }\end{array}$ & \% PIGMENTO & $\begin{array}{l}\text { \% AGLUTINANTE } \\
\text { PURO }\end{array}$ & $\begin{array}{l}\text { \% NO SÓLIDOS } \\
\text { (DISOLVENTES) }\end{array}$ \\
\hline W\&N Griffin & $73 \%$ & $42 \%$ & $31 \%$ & $27 \%$ \\
\hline $75 \% W \mho N$ Liquin-25\% aceite. & $83 \%$ & $70 \%$ & $13 \%$ & $17 \%$ \\
\hline $50 \%$ Wひ $N$ Liquin- $50 \%$ aceite. & $88 \%$ & $70 \%$ & $18 \%$ & $12 \%$ \\
\hline 25\% W\&N Liquin-75\% aceite. & $94 \%$ & $69 \%$ & $25 \%$ & $6 \%$ \\
\hline 75\% Kremer 79162-25\% aceite. & $89 \%$ & $70 \%$ & $19 \%$ & $11 \%$ \\
\hline $50 \%$ Kremer $79162-50 \%$ aceite. & $92 \%$ & $71 \%$ & $21 \%$ & $8 \%$ \\
\hline $25 \%$ Kremer $79162-75 \%$ aceite. & $95 \%$ & $67 \%$ & $28 \%$ & $5 \%$ \\
\hline
\end{tabular}

del aglutinante radicaba en la necesidad de un mayor porcentaje de aceite de linaza en la mezcla.

La cromatografía de gases nos ha indicado los disolventes empleados en cada producto. La pintura WerN Griffin contiene Mek, Xileno e Indusol 150-200. El Winsor \& Newton Liquin contiene Mek, Xileno e Indusol 160-180. El Kremer 79162 contiene Indusol 150-200 e Indusol 160-180. Por lo tanto, en lo que a contenido en disolventes, Winsor \& Newton Liquin tiene más similitud con los óleos alquídicos W\&N Griffin que Kremer 79162.

Los resultados de la prueba de sólidos se han sintetizado en la tabla III.

Como se puede observar, los W\&N Griffin contienen un porcentaje de pigmento sensiblemente inferior al del resto de muestras, nada menos que 30 puntos porcentuales, que es una cantidad bastante considerable (este dato será útil un poco más adelante). Sin embargo, las diferencias entre la cantidad de aglutinante de We N Griffin y la de las mezclas 25\% resina alquídica - 75\% aceite de linaza no son muy significativas. Hay que señalar también que en ambos aspectos la muestra más similar a los óleos alquídicos Griffin es la 25\% Kremer 79162-75\% aceite de linaza, seguida muy de cerca por la $25 \% \mathrm{~W} \delta N$ Liquin-75\% aceite de linaza.

Queda claro que las pinturas que mejores resultados han obtenido en los análisis técnicos han sido las aglutinadas con 25\% Wes $N$ Liquin-75\% aceite de linaza y con $25 \%$ Kremer $79162-75 \%$ aceite de linaza. La primera ha sido superior en la prueba comparativa y en la cromatografía de gases, y la segunda en la prueba de sólidos. 


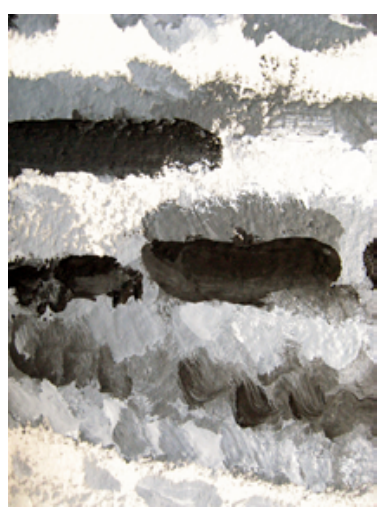

Fig. 9. $75 \%$ Liquin-

$25 \%$ aceite.

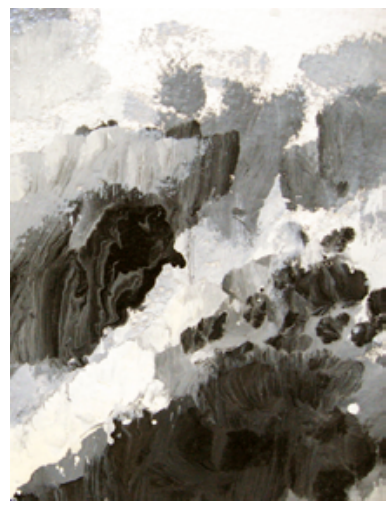

Fig. 12. 75\% Kremer 79162 $25 \%$ aceite.

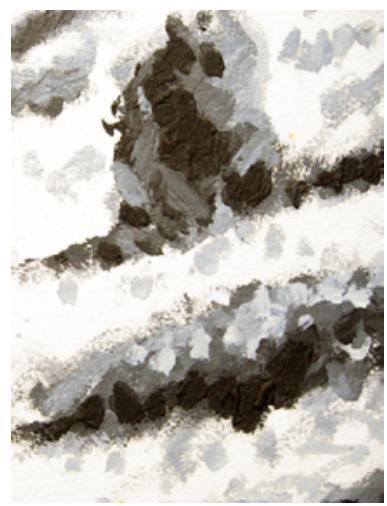

Fig. 10. 50\% Liquin$50 \%$ aceite.

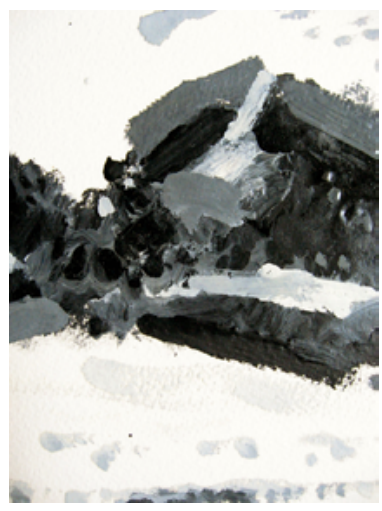

Fig. 13. 50\% Kremer 79162$50 \%$ aceite.

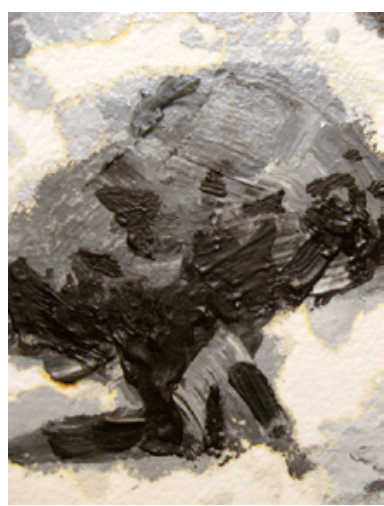

Fig. 11. 25\% Liquin$75 \%$ aceite.

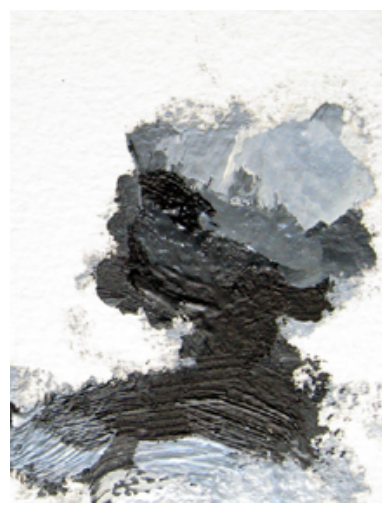

Fig. 14. 25\% Kremer 79162$75 \%$ aceite.

\subsection{Pruebas prácticas}

Han consistido en pintar una serie de lienzos con pinturas producidas con los seis aglutinantes testeados (figs. 9-14) ${ }^{18}$ más la referencia We̛N Griffin. Para agilizar el proceso, en lugar de los siete colores del apartado 1.3. se han utilizado sólo dos: el negro marfil -ya usado en los análisis técnicos-y el Blanco de titanio.

${ }^{18}$ Nuevamente, por motivos de espacio, no se pueden incluir las fotos de todos los cuadros. A modo de muestra se incluyen aquí detalles de seis de ellos, para que se aprecien mejor el cuerpo y la textura que pueden conseguir las diferentes muestras. Para ver todas las pinturas véase Mariano Espinosa, Tesis doctoral Las resinas alquidicas aplicadas a la pintura artística (Barcelona: Universitat de Barcelona: Departament de pintura, 2010), 376-394. (8). 


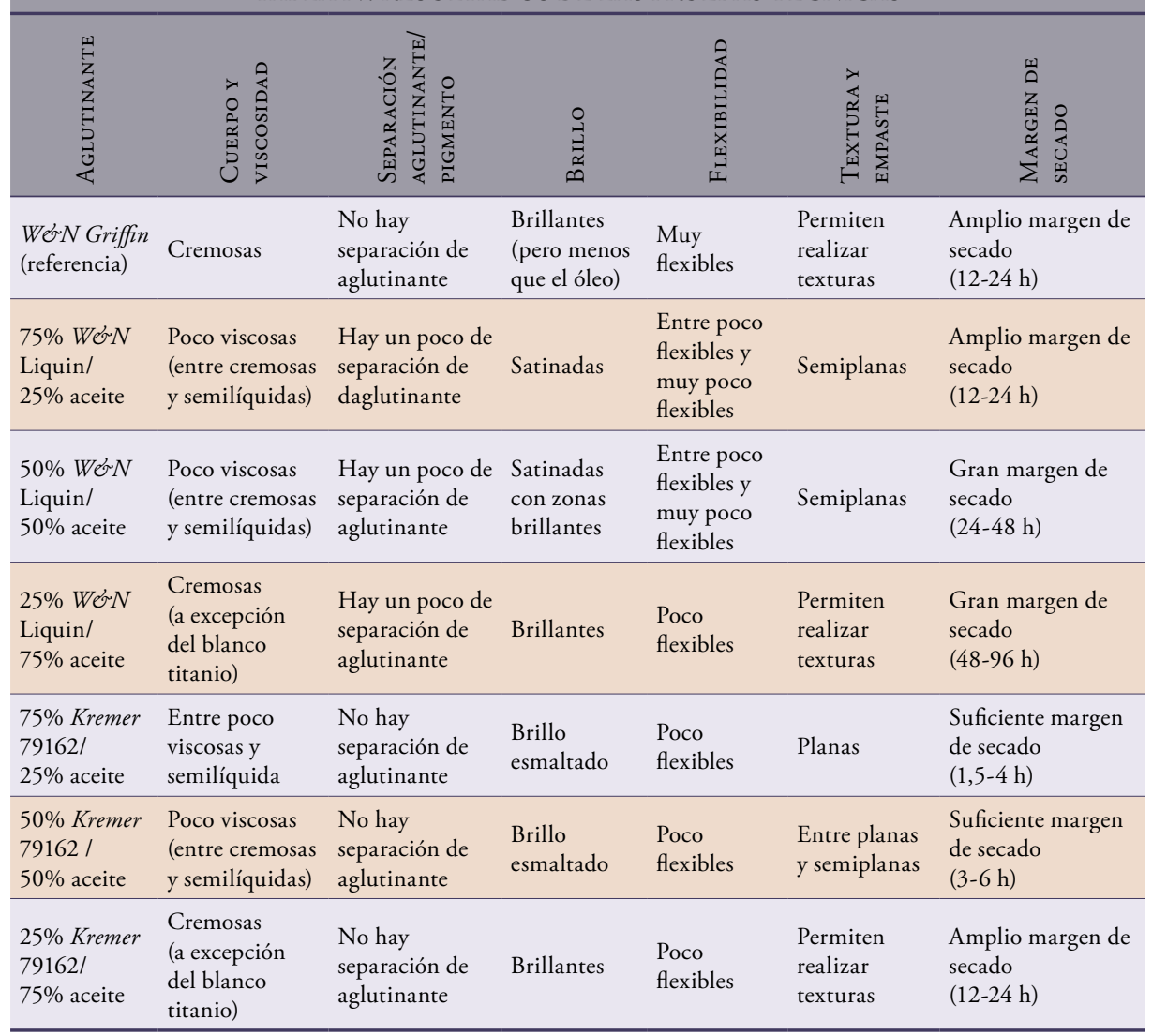

La tabla IV muestra un resumen de las observaciones que se han realizado.

Según esta tabla, las mezclas que mejores resultados han obtenido han sido las de $25 \%$ alquídico-75\% aceite. Muestran unos resultados razonablemente parecidos a los de los W\&N Griffin en todas las variables salvo en la flexibilidad. Se confirma de esta manera lo que ya apuntaban los análisis técnicos: que las pinturas más parecidas a los óleos alquídicos We $N$ Griffin son las aglutinadas con $25 \%$ W\& $N$ Liquin-75\% aceite de linaza y las aglutinadas con 25\% Kremer 79162-75\% aceite de linaza. Las primeras son algo superiores en las variables "Cuerpo y viscosidad» y «Textura y empaste», y muy superiores en la de "Margen de secado» (en la que también superan a las WéN Griffin). Las segundas sólo son algo superiores en la variable «Separación de aglutinante y pigmento».

Por tanto, todo parece indicar que el aglutinante que permitirá autoproducir óleos alquídicos similares a los WéN Griffin será el 25\% WéN Liquin-75\% Aceite de linaza. 
La única variable en la que las pinturas aglutinadas con esta mezcla se han mostrado claramente inferiores a los W\& $N$ Griffin es la de flexibilidad. Esto se debe a que, como indica la tabla III, esas pinturas autoproducidas llevan comparativamente un porcentaje de pigmento mucho mayor que las pinturas fabricadas industrialmente W\&N Griffin, lo que hace que sus películas sean más quebradizas al no ir el pigmento tan envuelto en la flexibilidad del aglutinante. Pero esta es una característica de absolutamente todas las pinturas autoproducidas, por lo que no es realmente un obstáculo; con los óleos tradicionales autoproducidos pasa exactamente lo mismo.

Otra variable que conviene estudiar un poco más es el gran margen de secado de las pinturas aglutinadas con 25\% W\& $N$ Liquin-75\% aceite de linaza, que es superior al de W\& $N$ Griffin. Esto puede ser indicativo de un secado más lento, lo que sería contraproducente, puesto que la rapidez de secado es la cualidad más importante de los óleos alquídicos. Pero una cosa es el secado, que es el tiempo que la pintura tarda en secar sobre el soporte pictórico, y otra el margen de secado, es decir, el tiempo que tarda en secar sobre la paleta, que es un soporte no poroso. Donde es importante que sequen rápido los óleos alquídicos es en el soporte pictórico, no en la paleta. Por tanto, para decidir mejor cuál de los dos aglutinantes que han obtenido mejores resultados en los análisis técnicos y las pruebas prácticas es el mejor para la autoproducción de óleos alquídicos, se ha estudiado también el secado de los mismos comparándolo con el de los W\&N Griffin. Esto se ha hecho sobre tela de lino imprimada tanto con la creta como con media creta, y extendiendo la pintura en tres grosores distintos: capa de pintura delgada, capa de pintura empastada y capa de empaste grueso. Las tablas $\mathrm{v}$ y vi muestran los resultados (ver página siguiente).

Estos resultados demuestran que la pintura que seca de forma más parecida al modelo de referencia Griffin es la aglutinada con 25\% W\& N Liquin-75\% aceite de linaza, tanto sobre tela de lino imprimado a la creta como sobre tela de lino imprimado a la media creta. Es más, sobre lino imprimado a la media creta los resultados han sido prácticamente iguales. La pintura aglutinada con 25\% Kremer $79162-75 \%$ aceite de linaza seca sensiblemente más rápido que los W\&N Griffin.

Otra observación que se ha podido realizar es que cuanto más poroso es el soporte, más rápido seca tanto la mezcla de Winsor \& Newton Liquin como la de Kremer 79162. Este era el motivo de que la pintura aglutinada con 25\% W\& $N$ Liquin-75\% aceite de linaza secase al mismo ritmo que los Griffin sobre tela, pero más lenta sobre la paleta. Los W\& $N$ Griffin, sin embargo, muestran un secado más homogéneo independientemente de la porosidad del soporte. Esta es otra de las diferencias que se dan entre las pinturas autoproducidas y las industriales, no sólo en los óleos alquidicos, sino también en los óleos tradicionales.

Por tanto ya se puede afirmar de forma taxativa que el aglutinante que permite autoproducir óleos alquídicos similares a los W\&N Griffin es la mezcla 25\% $W \mho N N$ Liquin-75\% aceite de linaza. $Y$ en el siguiente apartado se ha profundizado tanto en su producción como en sus características con la gama de 28 pigmentos que se ha citado en 0.1 . 


\begin{tabular}{|c|c|c|c|}
\hline \multicolumn{4}{|c|}{$\begin{array}{l}\text { TABLA V. RESULTADOS DEL SECADO DE LAS MUESTRAS SOBRE LINO IMPRIMADO A LA CRETA } \\
\text { PIGMENTO: NEGRO MARFIL SOPORTE: TELA DE LINO IMPRIMACIÓN: CRETA }\end{array}$} \\
\hline Aglutinante: & $\begin{array}{l}\text { CAPA DE PINTURA } \\
\text { DELGADA }\end{array}$ & $\begin{array}{l}\text { CAPA DE PINTURA } \\
\text { EMPASTADA }\end{array}$ & $\begin{array}{l}\text { CAPA DE EMPASTE } \\
\text { GRUESO }\end{array}$ \\
\hline $\begin{array}{l}25 \% \text { WگN Liquin- } \\
75 \% \text { aceite }\end{array}$ & $\begin{array}{l}\text { Tarda en secar } \\
\text { entre } 8 \text { y } 16 \mathrm{~h}\end{array}$ & $\begin{array}{l}\text { Tarda en secar } \\
\text { entre } 16 \text { y } 24 \mathrm{~h}\end{array}$ & $\begin{array}{l}\text { Tarda en secar } \\
\text { entre } 48 \text { y } 56 \mathrm{~h}\end{array}$ \\
\hline $\begin{array}{l}25 \% \text { Kremer- } \\
75 \% \text { aceite }\end{array}$ & $\begin{array}{l}\text { Tarda en secar } \\
\text { menos de } 4 \mathrm{~h}\end{array}$ & $\begin{array}{l}\text { Tarda en secar } \\
\text { entre } 8 \text { y } 16 \mathrm{~h}\end{array}$ & $\begin{array}{l}\text { Tarda en secar } \\
\text { entre } 24 \text { y } 32 \mathrm{~h}\end{array}$ \\
\hline \multicolumn{4}{|c|}{ Producto de REFERENCIA } \\
\hline W\&N Griffin & $\begin{array}{l}\text { Tarda en secar } \\
\text { entre } 8 \text { y } 16 \mathrm{~h}\end{array}$ & $\begin{array}{l}\text { Tarda en secar } \\
\text { entre } 32 \text { y } 40 \mathrm{~h}\end{array}$ & $\begin{array}{l}\text { Máximo secado: } 80 \mathrm{~h} \\
\text { Seca en superficie: } 48 \mathrm{~h}\end{array}$ \\
\hline
\end{tabular}

\begin{tabular}{cccc}
\hline \multicolumn{4}{c}{ TABLA VI. RESULTADOS DEL SECADO DE LAS MUESTRAS } \\
SOBRE LINO IMPRIMADO A LA MEDIA CRETA \\
PIGMENTO: NEGRO MARFIL SOPORTE: TELA DE LINO IMPRIMACIÓN: 1/2 CRETA
\end{tabular}

\section{3. ÓLEOS ALQUÍDICOS AUTOPRODUCIDOS}

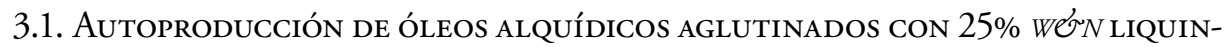 75\% ACEITE DE LINAZA}

El proceso es exactamente el mismo que se sigue en la autoproducción de las pinturas al óleo tradicionales: se pesa la cantidad de pigmento y carga que se va a utilizar $y$, sobre ellos, se vierte el aglutinante, amasando primero con rasqueta para aglutinar el pigmento y después con moleta para refinar la pintura. Al final del proceso se puede añadir un $2 \%$ de cera a la pintura como estabilizante.

En la tabla vir se indica la proporción de aglutinante que necesita cada pigmento, así como las observaciones que se han realizado durante su autoproducción. 


\begin{tabular}{|c|c|c|c|c|c|}
\hline \multicolumn{6}{|c|}{$\begin{array}{l}\text { TABLA VII. PROPORCIONES DE LAS PINTURAS AGLUTINADAS CON } \\
\text { 25\% } W \mho \mho N N \text { LIQUIN-75\% ACEITE LINAZA }\end{array}$} \\
\hline Pigmento & Cantidad & $\begin{array}{l}\text { CARGA: } \\
\text { HIDRATO } \\
\text { DE ALUUMINA }\end{array}$ & $\begin{array}{l}\text { AgLutinante } \\
25 \% \text { LiQuin- } \\
75 \% \text { ACEITE } \\
\text { DE LINAZA }\end{array}$ & OBSERVACIONES & Resultado \\
\hline \multicolumn{6}{|l|}{ Blancos } \\
\hline $\begin{array}{l}\text { Blanco de } \\
\text { plomo } \\
\text { (PW1) }\end{array}$ & $100 \mathrm{~g}$ & $33 \mathrm{~g}$ & $25 \mathrm{~g}$ & $\begin{array}{l}\text { La parte de aceite es aceite de ador- } \\
\text { midera Talens. Reacciona bien con } \\
\text { el aglutinante. Fácil de fabricar. }\end{array}$ & \\
\hline $\begin{array}{l}\text { Blanco } \\
\text { titanio } \\
\text { (PW6) }\end{array}$ & $100 \mathrm{~g}$ & $33 \mathrm{~g}$ & $28-30 \mathrm{~g}$ & $\begin{array}{l}\text { Aceite de adormidera Talens. Difícil } \\
\text { de fabricar. Conviene intentar } \\
\text { emplear la menor cantidad de } \\
\text { aglutinante posible. La pintura } \\
\text { queda algo filamentosa. }\end{array}$ & \\
\hline $\begin{array}{l}\text { Blanco de } \\
\text { zinc } \\
\text { (PW4) }\end{array}$ & $100 \mathrm{~g}$ & $33 \mathrm{~g}$ & $30 \mathrm{~g}$ & $\begin{array}{l}\text { Aceite de adormidera Talens. Tam- } \\
\text { bién difícil de fabricar. Empléese } \\
\text { la menor cantidad de aglutinante } \\
\text { posible. Al principio le faltaba algo } \\
\text { de cuerpo, pero una vez entuba- } \\
\text { do ganó viscosidad, quedando } \\
\text { cremoso. }\end{array}$ & \\
\hline \multicolumn{6}{|l|}{ Amarillos } \\
\hline $\begin{array}{l}\text { Amarillo } \\
\text { cadmio } \\
\text { (PY35) }\end{array}$ & $100 \mathrm{~g}$ & $33 \mathrm{~g}$ & $45 \mathrm{~g}$ & $\begin{array}{l}\text { Es muy fácil excederse con la } \\
\text { cantidad de aglutinante, por lo que } \\
\text { conviene utilizar escrupulosamente } \\
\text { la cantidad indicada. }\end{array}$ & \\
\hline $\begin{array}{l}\text { Amarillo } \\
\text { Hansa } \\
\text { (PY65) }\end{array}$ & $100 \mathrm{~g}$. & $33 \mathrm{~g}$ & $110 \mathrm{~g}$ & $\begin{array}{l}\text { Reacciona muy bien con el agluti- } \\
\text { nante. Queda igual que las pinturas } \\
\text { Griffin; la cantidad de aglutinante } \\
\text { puede variar sin peligro. }\end{array}$ & \\
\hline $\begin{array}{l}\text { Amarillo } \\
\text { cromo }\end{array}$ & $100 \mathrm{~g}$ & $33 \mathrm{~g}$ & $30 \mathrm{~g}$ & $\begin{array}{l}\text { Muy difícil de fabricar. Es fácil } \\
\text { excederse con la cantidad de } \\
\text { aglutinante, y aun teniendo } \\
\text { cuidado queda poco viscosa. }\end{array}$ & \\
\hline $\begin{array}{l}\text { Amarillo } \\
\text { Nápoles } \\
\text { (PY53) }\end{array}$ & $100 \mathrm{~g}$ & $33 \mathrm{~g}$ & $45-50 \mathrm{~g}$ & $\begin{array}{l}\text { Hay que usar la mínima cantidad } \\
\text { de aglutinante posible y amasar con } \\
\text { fuerza. Si queda muy viscosa, añá- } \\
\text { dase un poco más de aglutinante. }\end{array}$ & \\
\hline $\begin{array}{l}\text { Ocre } \\
\text { amarillo } \\
\text { (PY43) }\end{array}$ & $100 \mathrm{~g}$ & $33 \mathrm{~g}$ & $35 \mathrm{~g}$ & $\begin{array}{l}\text { Fácil de fabricar. Reacciona bien } \\
\text { con el aglutinante. }\end{array}$ & \\
\hline \multicolumn{6}{|l|}{ Rojos } \\
\hline $\begin{array}{l}\text { Rojo } \\
\text { cadmio } \\
\text { (PR108) }\end{array}$ & $100 \mathrm{~g}$ & $33 \mathrm{~g}$ & $35-40 \mathrm{~g}$ & $\begin{array}{l}\text { Es fácil pasarse con la cantidad de } \\
\text { aglutinante, por lo que hay que } \\
\text { tener cuidado. Si queda muy viscosa } \\
\text { por un exceso de celo, basta añadir } \\
\text { unas gotas de aglutinante. }\end{array}$ & \\
\hline $\begin{array}{l}\text { Rojo } \\
\text { naftol } \\
\text { (PR112) }\end{array}$ & $100 \mathrm{~g}$ & $33 \mathrm{~g}$ & $150 \mathrm{~g}$ & $\begin{array}{l}\text { Reacciona muy bien con el agluti- } \\
\text { nante. Queda igual que las pinturas } \\
\text { Griffin. }\end{array}$ & \\
\hline
\end{tabular}




\begin{tabular}{|c|c|c|c|c|}
\hline $\begin{array}{l}\text { Carmín } \\
\text { alizarina } \\
\text { (PR83) }\end{array}$ & $100 \mathrm{~g}$ & $33 \mathrm{~g}$ & $100 \mathrm{~g}$ & $\begin{array}{l}\text { Reacciona muy bien con el } \\
\text { aglutinante. Consigue la misma } \\
\text { viscosidad que su homólogo Griffin, } \\
\text { aunque con un poco más de grano } \\
\text { por el molido a mano. }\end{array}$ \\
\hline $\begin{array}{l}\text { Rojo } \\
\text { hierro } \\
\text { (PR101) }\end{array}$ & $100 \mathrm{~g}$ & $33 \mathrm{~g}$ & $40 \mathrm{~g}$ & $\begin{array}{l}\text { Muy difícil de fabricar. Es } \\
\text { fácil pasarse con la cantidad } \\
\text { de aglutinante, y aun teniendo } \\
\text { cuidado queda poco viscosa. }\end{array}$ \\
\hline $\begin{array}{l}\text { Ocre } \\
\text { rojo } \\
\text { (PR102) }\end{array}$ & $100 \mathrm{~g}$ & $33 \mathrm{~g}$ & $60 \mathrm{~g}$ & $\begin{array}{l}\text { Parecido al rojo de hierro aunque } \\
\text { ha quedado mejor. } \\
\text { Hay que usar muy poco aglutinante } \\
\text { y apretar mucho al amasar. }\end{array}$ \\
\hline \multicolumn{5}{|l|}{ Violeta } \\
\hline $\begin{array}{l}\text { Violeta } \\
\text { manganeso } \\
\text { (PV16) }\end{array}$ & $100 \mathrm{~g}$ & $33 \mathrm{~g}$ & $55 \mathrm{~g}$ & $\begin{array}{l}\text { Reacciona muy bien con el } \\
\text { aglutinante. Queda igual que las } \\
\text { pinturas Griffin. }\end{array}$ \\
\hline \multicolumn{5}{|l|}{ Azules } \\
\hline $\begin{array}{l}\text { Azul } \\
\text { cobalto } \\
\text { (PB28) }\end{array}$ & $100 \mathrm{~g}$ & $33 \mathrm{~g}$ & $45 \mathrm{~g}$ & $\begin{array}{l}\text { Tiende a quedar un poco } \\
\text { filamentoso. Conviene no pasarse } \\
\text { con el aglutinante. Es mejor que } \\
\text { quede un poco de más de espeso } \\
\text { que de menos, pues una pequeña } \\
\text { separación de aglutinante lo } \\
\text { corrige. }\end{array}$ \\
\hline $\begin{array}{l}\text { Azul } \\
\text { ultramar } \\
\text { (PB29) }\end{array}$ & $100 \mathrm{~g}$ & $33 \mathrm{~g}$ & $45 \mathrm{~g}$ & $\begin{array}{l}\text { Parecido al azul cobalto. También } \\
\text { queda un poco filamentoso, y algo } \\
\text { menos cremoso. }\end{array}$ \\
\hline $\begin{array}{l}\text { Azul } \\
\text { Prusia } \\
\text { (PB27) }\end{array}$ & $100 \mathrm{~g}$ & $33 \mathrm{~g}$ & $110-115 \mathrm{~g}$ & $\begin{array}{l}\text { Reacciona muy bien con el } \\
\text { aglutinante. Queda muy parecido } \\
\text { a su homóloga Griffin, aunque un } \\
\text { poco más granulada por el molido } \\
\text { a mano. Se le puede añadir más } \\
\text { aglutinante para que quede más } \\
\text { similar al Griffin (menos viscosidad } \\
\text { y grano). }\end{array}$ \\
\hline $\begin{array}{l}\text { Azul } \\
\text { ftalocianina } \\
\text { (PB15) }\end{array}$ & $100 \mathrm{~g}$ & $33 \mathrm{~g}$ & $90-150 \mathrm{~g}$ & $\begin{array}{l}\text { Reacciona muy bien con el agluti- } \\
\text { nante. Queda como su homólogo } \\
\text { Griffin. Con } 90 \mathrm{~g} \text { de aglutinante es } \\
\text { suficiente para pintar, pero queda } \\
\text { más parecido a Griffin con } 150 \mathrm{~g} \text {. }\end{array}$ \\
\hline $\begin{array}{l}\text { Azul } \\
\text { cerúleo } \\
\text { (PB35) }\end{array}$ & $100 \mathrm{~g}$ & $33 \mathrm{~g}$ & $40 \mathrm{~g}$ & $\begin{array}{l}\text { Difícil de fabricar. Conviene } \\
\text { tener cuidado de no pasarse con } \\
\text { el aglutinante, y aun así no queda } \\
\text { cremoso. }\end{array}$ \\
\hline \multicolumn{5}{|l|}{ Verdes } \\
\hline $\begin{array}{l}\text { Verde } \\
\text { óxido } \\
\text { cromo }\end{array}$ & $100 \mathrm{~g}$ & $33 \mathrm{~g}$ & $30 \mathrm{~g}$ & $\begin{array}{l}\text { Reacciona bien con el aglutinante, } \\
\text { aunque no alcanza la misma } \\
\text { cremosidad de las pinturas } \\
\text { industriales. Parecido a los cadmios } \\
\text { en este sentido. }\end{array}$ \\
\hline
\end{tabular}




\begin{tabular}{|c|c|c|c|c|}
\hline $\begin{array}{l}\text { Verde } \\
\text { ftalocianina } \\
(\mathrm{PG} 7)\end{array}$ & $100 \mathrm{~g}$ & $33 \mathrm{~g}$ & $90 \mathrm{~g}$ & $\begin{array}{l}\text { Reacciona muy bien con el } \\
\text { aglutinante. Queda igual que su } \\
\text { homólogo Griffin, auque un poco } \\
\text { más granulado. }\end{array}$ \\
\hline \multicolumn{5}{|l|}{ Ocres } \\
\hline $\begin{array}{l}\text { Siena } \\
\text { natural } \\
(\mathrm{PBr} 7)\end{array}$ & $100 \mathrm{~g}$ & $33 \mathrm{~g}$ & $55 \mathrm{~g}$ & $\begin{array}{l}\text { Reacciona muy bien con el } \\
\text { aglutinante. Queda igual que su } \\
\text { homólogo Griffin. Se le puede } \\
\text { ańadir un poco más de aglutinante } \\
\text { del estrictamente necesario, } \\
\text { para que adquiera más brillo y } \\
\text { cremosidad. }\end{array}$ \\
\hline $\begin{array}{l}\text { Siena } \\
\text { tostada } \\
(\mathrm{PBr} 7)\end{array}$ & $100 \mathrm{~g}$ & $33 \mathrm{~g}$ & $50-55 \mathrm{~g}$ & $\begin{array}{l}\text { Reacciona muy bien con el } \\
\text { aglutinante. Queda igual que su } \\
\text { homólogo Griffin. Se le puede } \\
\text { añadir un poco más de aglutinante } \\
\text { del estrictamente necesario, } \\
\text { para que adquiera más brillo y } \\
\text { cremosidad. }\end{array}$ \\
\hline $\begin{array}{l}\text { Sombra } \\
\text { nNatural } \\
(\mathrm{PBr} 7)\end{array}$ & $100 \mathrm{~g}$ & $33 \mathrm{~g}$ & $55-60 \mathrm{~g}$ & $\begin{array}{l}\text { Reacciona muy bien con el } \\
\text { aglutinante. Queda igual que su } \\
\text { homólogo Griffin. }\end{array}$ \\
\hline $\begin{array}{l}\text { Sombra } \\
\text { tostada } \\
(\mathrm{PBr} 7)\end{array}$ & $100 \mathrm{~g}$ & $33 \mathrm{~g}$ & $55 \mathrm{~g}$ & $\begin{array}{l}\text { Reacciona muy bien con el } \\
\text { aglutinante. Queda igual que su } \\
\text { homólogo Griffin. }\end{array}$ \\
\hline \multicolumn{5}{|l|}{ Negros } \\
\hline $\begin{array}{l}\text { Negro } \\
\text { marfil } \\
\text { (PBk9) }\end{array}$ & $100 \mathrm{~g}$ & $33 \mathrm{~g}$ & $65 \mathrm{~g}$ & $\begin{array}{l}\text { Reacciona muy bien con el } \\
\text { aglutinante. Queda igual que su } \\
\text { homólogo Griffin. }\end{array}$ \\
\hline $\begin{array}{l}\text { Negro } \\
\text { hierro } \\
(\text { PBk11) }\end{array}$ & $100 \mathrm{~g}$ & $33 \mathrm{~g}$ & $35-40 \mathrm{~g}$ & $\begin{array}{l}\text { Reacciona muy bien con el } \\
\text { aglutinante. Queda igual que las } \\
\text { pinturas Griffin. }\end{array}$ \\
\hline $\begin{array}{l}\text { Negro } \\
\text { humo } \\
\text { (PBk6) }\end{array}$ & $100 \mathrm{~g}$ & $33 \mathrm{~g}$ & $35 \mathrm{~g}$ & $\begin{array}{l}\text { Reacciona muy bien con el agluti- } \\
\text { nante. Queda igual que su homólogo } \\
\text { Griffin. }\end{array}$ \\
\hline
\end{tabular}

\subsection{Cuerpo y Viscosidad de LAS PINTURAS AGLUTINADAS CON $25 \%$ W $\mho ́ N$ LIQUIN- $75 \%$ ACEITE DE LINAZA}

La fig. 15 muestra la viscosidad que presenta al salir del tubo de pintura cada uno de los colores aglutinados.

A la vista de los resultados los colores se han clasificado, según su viscosidad, tal y como aparecen en la tabla viII. 


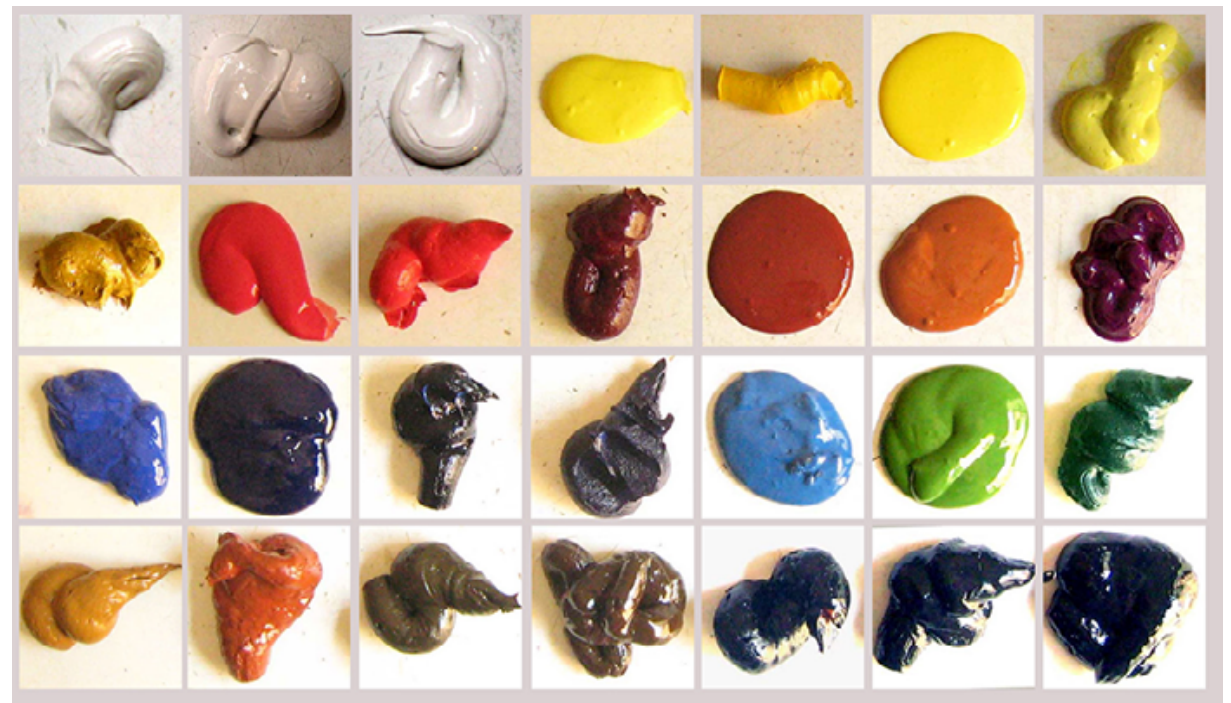

Fig. 15. Cuerpo y viscosidad de las pinturas aglutinadas con $25 \%$ W $N$ Liquin-75\% aceite de linaza.

Fila 1: blanco de Plomo, blanco de titanio, blanco de zinc, amarillo cadmio, amarillo Hansa, amarillo cromo y amarillo Nápoles. Fila 2: ocre amarillo, rojo cadmio, rojo naftol, carmín de alizarina, rojo de hierro, ocre rojo y violeta de manganeso. Fila 3: azul cobalto, azul ultramar, azul de Prusia, azul de ftalocianina, azul cerúleo, verde de óxido de cromo y verde de ftalocianina. Fila 4: siena natural, siena tostada, sombra natural, sombra tostada, negro marfil, negro de hierro y negro de humo.

\begin{tabular}{lllll}
\hline \multicolumn{5}{c}{ TABLA VIII. CUERPO Y VISCOSIDAD DE ÓlEOS ALQUÍDICOS } \\
25\% W\&N LIQUIN-75\% ACEITE LINAZA
\end{tabular}




\begin{tabular}{|c|c|c|}
\hline \multicolumn{3}{|c|}{ TABLA IX. SEPARACIÓN DE AGLUTINANTE Y PIGMENTO } \\
\hline $\begin{array}{l}\text { Pigmentos EN los QUe NO HaY } \\
\text { SEPARACIÓN DE AGLUTINANTE }\end{array}$ & $\begin{array}{l}\text { Pigmentos En LOS QUE HAY UN POCO } \\
\text { DE SEPARACIÓN DE AGLUTINANTE }\end{array}$ & $\begin{array}{l}\text { Pigmentos en LOS QUE HaY MUCHA } \\
\text { SEPARACIÓN DE AGLUTINANTE }\end{array}$ \\
\hline $\begin{array}{l}\text { Blanco titanio } \\
\text { Blanco de zinc } \\
\text { Amarillo cadmio } \\
\text { Amarillo Hansa } \\
\text { Amarillo cromo } \\
\text { Ocre amarillo } \\
\text { Rojo naftol } \\
\text { Carmín de alizarina } \\
\text { Azul ultramar } \\
\text { Azul de Prusia } \\
\text { Azul de ftalocianina } \\
\text { Verde de ftalocianina } \\
\text { Siena natural } \\
\text { Siena tostada } \\
\text { Sombra natural } \\
\text { Sombra tostada } \\
\text { Negro marfil } \\
\text { Negro hierro }\end{array}$ & $\begin{array}{l}\text { Rojo óxido de hierro } \\
\text { Ocre rojo } \\
\text { Azul cobalto } \\
\text { Verde óxido de cromo } \\
\text { Negro humo }\end{array}$ & $\begin{array}{l}\text { Blanco plomo } \\
\text { Amarillo Nápoles } \\
\text { Rojo cadmio } \\
\text { Violeta manganeso } \\
\text { Azul cerúleo }\end{array}$ \\
\hline
\end{tabular}

\subsection{Separación de pigmento y aglutinante En las pinturas aglutinadas CON 25\% W\&N LIQUIN-75\% ACEITE DE LINAZA}

Para estudiar esta variante, los colores autoproducidos se han entubado en tubos de aluminio y se han mantenido así guardados durante seis semanas, al cabo de las cuales se ha comprobado la estabilidad de los mismos. La gran mayoría se han mantenido estables, pero en algunos casos sí que se han producido separaciones de aglutinante y pigmento. Estas separaciones se pueden observar fácilmente cuando al presionar el tubo para extraer la pintura sale primero un reguero de aglutinante que se ha separado. Este fenómeno suele aparejar un aumento en la viscosidad o endurecimiento de la pintura, lo cual puede afectar negativamente a su manejabilidad.

La tabla IX muestra la clasificación de los colores según su mayor, menor o nula separación de aglutinante y pigmento:

\subsection{Secado de las pinturas aglutinadas CON 25\% W\&N LiQuin-75\% aCeite DE LINAZA}

Para estudiar el secado de estas pinturas se han aplicado sobre tela de lino, primero con imprimación a la creta -tabla XI- (fig. 16) y después con imprimación a la media creta -tabla XII-. Y las pinturas se han extendido en forma de capa de pintura delgada, capa de pintura empastada y capa de empaste grueso, para poder observar también las variaciones del secado en función del grosor de la capa de pintura. Las condiciones ambientales han sido temperatura: $20-25^{\circ} \mathrm{C}$, humedad: $40-50 \%$, luz difusa de día y oscuridad de noche. 


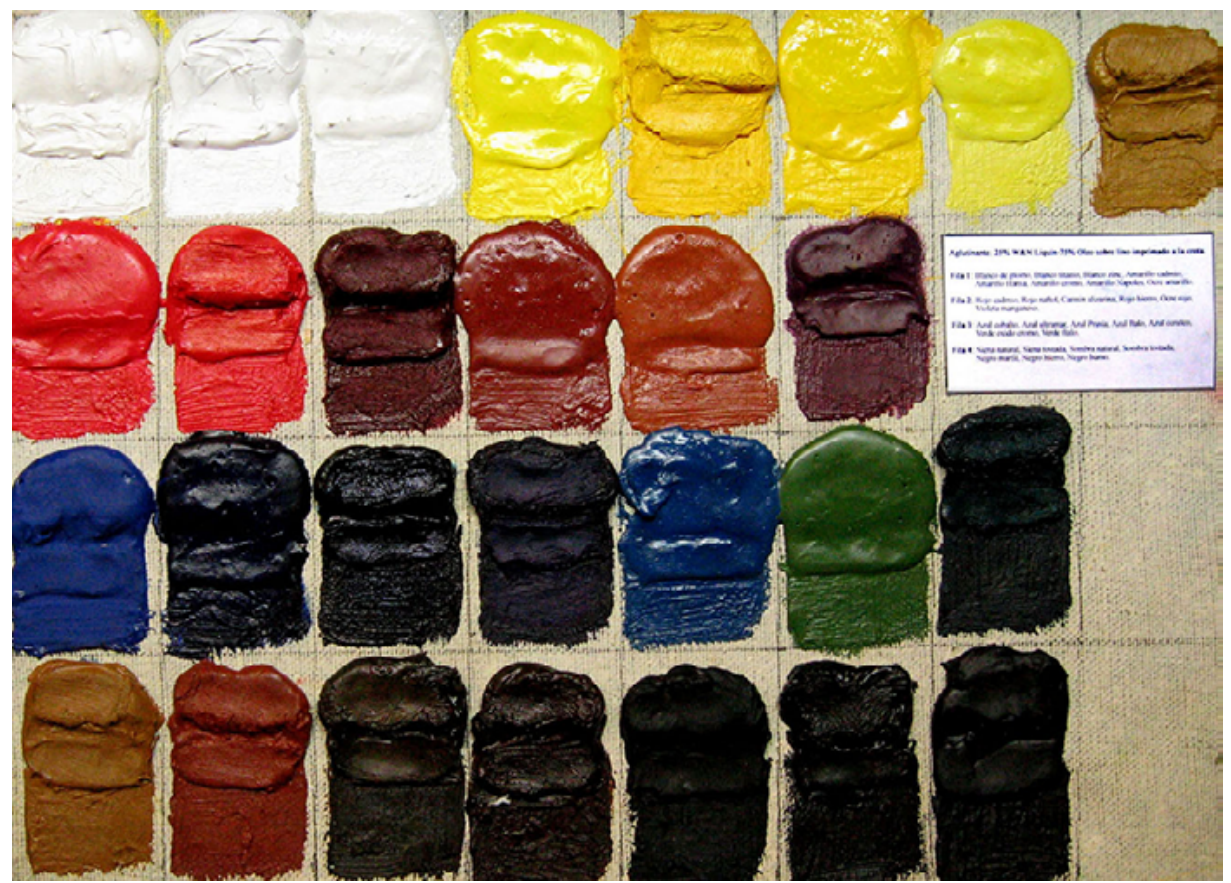

Fig. 16. Secado de los óleos alquídicos caseros sobre lino imprimado a la creta.

Fila 1: blanco de plomo, blanco titanio, blanco zinc, amarillo cadmio, amarillo Hansa, amarillo cromo, amarillo Nápoles, ocre amarillo. Fila 2: rojo cadmio, rojo naftol, rojo de óxido de hierro (rojo inglés), ocre rojo, carmín de alizarina, violeta de manganeso. Fila 3: azul cobalto, azul ultramar, azul Prusia, azul ftalocianina, azul cerúleo, verde óxido de cromo, verde ftalocianina. Fila 4: siena natural, siena tostada, sombra natural, sombra tostada, negro marfil, negro hierro, negro manganeso.

Una vez sintetizados todos los datos obtenidos del estudio del secado de las pinturas aglutinadas con $25 \% W \mho N$ Liquin-75\% aceite de linaza la principal observación que puede hacerse es que, si se comparan con el secado de los W\&N Griffin ${ }^{19}$, estas pinturas tienen unos tiempos de secado muy parecidos. No son exactamente iguales en todos los colores, pero los que difieren un poco no presentan variaciones excesivas.

${ }^{19}$ Las tablas de secado de los alquídicos Griffin se pueden encontrar en Mariano Espinosa, «Los óleos alquídicos Griffin: composición, propiedades y aplicación» Revista de Bellas Artes 11 (2013): 139-141. https://riull.ull.es/xmlui/bitstream/handle/915/2410/BA_11_\%282013\%29_06. pdf? sequence $=5 \&$ isAllowed $=y$ (consultado el 15 de diciembre de 2020). Volverlas a incluir aquí obligaría a exceder la extensión permitida para este artículo. 


\begin{tabular}{lll}
\hline \multicolumn{3}{c}{ TABLA X. COMPARACIÓN ENTRE EL SECADO DE LOS ÓLEOS ALQUÍDICOS } \\
AUTOPRODUCIDOS Y LOS ÓlEOS ALQUÍDICOS W WN GRIFFIN
\end{tabular}

En la tabla x se han clasificado los colores estudiados en función de si secan igual de rápido que sus equivalentes en WeN Griffin (si los tienen ${ }^{20}$ ) o si secan un poco más rápido o un poco más lento.

En las tablas XI y XII se ha decidido incluir los resultados completos del secado de los óleos alquídicos auto-producidos. Una información que puede ser de utilidad para el pintor interesado en ésta técnica pictórica.

\begin{tabular}{|c|c|c|c|}
\hline \multicolumn{4}{|c|}{$\begin{array}{l}\text { TABLA XI. SECADO DE LOS ÓLEOS ALQUÍDICOS AGLUTINADOS CON } \\
\text { 25\% W'́N LIQUIN-75\% ACEITE SOPORTE: TELA DE LINO IMPRIMACIONN: CRETA }\end{array}$} \\
\hline Pigmentos & $\begin{array}{l}\text { CAPA DE PINTURA } \\
\text { DELGADA }\end{array}$ & $\begin{array}{l}\text { CAPA DE PINTURA } \\
\text { EMPASTADA }\end{array}$ & $\begin{array}{l}\text { CAPA DE EMPASTE } \\
\text { GRUESO }\end{array}$ \\
\hline Blanco plomo & $\begin{array}{l}\text { Tarda en secar } \\
\text { entre } 24 \text { y } 32 \mathrm{~h}\end{array}$ & $\begin{array}{l}\text { Tarda en secar } \\
\text { entre } 64 \mathrm{y} 72 \mathrm{~h}\end{array}$ & $\begin{array}{r}\text { Tarda en secar } \\
\text { entre } 80 \text { y } 88 \text { h }\end{array}$ \\
\hline Blanco titanio & $\begin{array}{l}\text { Tarda en secar } \\
\text { entre } 16 \text { y } 24 \mathrm{~h}\end{array}$ & $\begin{array}{l}\text { Tarda en secar } \\
\text { entre } 40 \text { y } 48 \mathrm{~h}\end{array}$ & $\begin{array}{l}\text { Tarda en secar } \\
\text { entre } 96 \text { y } 104 \mathrm{~h}\end{array}$ \\
\hline Blanco zinc & $\begin{array}{l}\text { Tarda en secar } \\
\text { menos de } 4 \mathrm{~h}\end{array}$ & $\begin{array}{l}\text { Tarda en secar } \\
\text { entre } 16 \text { y } 24 \mathrm{~h}\end{array}$ & $\begin{array}{l}\text { Tarda en secar } \\
\text { entre } 48 \text { y } 56 \text { h }\end{array}$ \\
\hline Amarillo cadmio & $\begin{array}{l}\text { Tarda en secar } \\
\text { menos de } 4 \mathrm{~h}\end{array}$ & $\begin{array}{l}\text { Tarda en secar } \\
\text { entre } 16 \text { y } 24 \mathrm{~h}\end{array}$ & $\begin{array}{l}\text { Tarda en secar } \\
\text { entre } 32 \text { y } 40 \mathrm{~h}\end{array}$ \\
\hline Amarillo Hansa & $\begin{array}{l}\text { Tarda en secar } \\
\text { entre } 24 \text { y } 32 \mathrm{~h}\end{array}$ & $\begin{array}{l}\text { Tarda en secar } \\
\text { entre } 64 \text { y } 72 \mathrm{~h}\end{array}$ & $\begin{array}{l}\text { Tarda en secar } \\
\text { entre } 96 \text { y } 104 \mathrm{~h}\end{array}$ \\
\hline Amarillo cromo & $\begin{array}{l}\text { Tarda en secar } \\
\text { entre } 4 \text { y } 8 \mathrm{~h}\end{array}$ & $\begin{array}{l}\text { Tarda en secar } \\
\text { entre } 56 \text { y } 64 \mathrm{~h}\end{array}$ & $\begin{array}{l}\text { Tarda en secar } \\
\text { entre } 72 \text { y } 80 \mathrm{~h}\end{array}$ \\
\hline
\end{tabular}

${ }^{20}$ El blanco de zinc, amarillo de cromo, amarillo Hansa, rojo naftol puro, violeta de manganeso y negro hierro no tenían su equivalente dentro de la gama de colores W\& $N$ Griffin en el momento en que se realizó el presente estudio. El amarillo de Nápoles es una imitación. 


\begin{tabular}{|c|c|c|c|}
\hline Amarillo Nápoles & $\begin{array}{l}\text { Tarda en secar } \\
\text { menos de } 4 \mathrm{~h}\end{array}$ & $\begin{array}{l}\text { Tarda en secar } \\
\text { entre } 4 \text { y } 8 \mathrm{~h}\end{array}$ & $\begin{array}{l}\text { Tarda en secar } \\
\text { entre } 8 \text { y } 16 \mathrm{~h}\end{array}$ \\
\hline Ocre amarillo & $\begin{array}{l}\text { Tarda en secar } \\
\text { menos de } 4 \mathrm{~h}\end{array}$ & $\begin{array}{l}\text { Tarda en secar } \\
\text { entre } 32 \text { y } 40 \mathrm{~h}\end{array}$ & $\begin{array}{l}\text { Tarda en secar } \\
\text { entre } 104 \text { y } 112 \mathrm{~h}\end{array}$ \\
\hline Rojo cadmio & $\begin{array}{l}\text { Tarda en secar } \\
\text { menos de } 4 \mathrm{~h}\end{array}$ & $\begin{array}{l}\text { Tarda en secar } \\
\text { entre } 8 \text { y } 16 \text { h }\end{array}$ & $\begin{array}{l}\text { Tarda en secar } \\
\text { entre } 40 \text { y } 48 \mathrm{~h}\end{array}$ \\
\hline Rojo naftol & $\begin{array}{l}\text { Tarda en secar } \\
\text { entre } 32 \text { y } 40 \mathrm{~h}\end{array}$ & $\begin{array}{l}\text { Tarda en secar } \\
\text { entre } 112 \text { y } 120 \mathrm{~h}\end{array}$ & $\begin{array}{c}\text { Tarda en secar } \\
\text { entre } 144 \text { y } 152 \mathrm{~h}\end{array}$ \\
\hline Carmín alizarina & $\begin{array}{l}\text { Tarda en secar } \\
\text { entre } 4 \text { y } 8 \mathrm{~h}\end{array}$ & $\begin{array}{l}\text { Tarda en secar } \\
\text { entre } 80 \text { y } 88 \mathrm{~h}\end{array}$ & $\begin{array}{l}\text { Tarda en secar } \\
\text { entre } 120 \text { y } 128 \mathrm{~h}\end{array}$ \\
\hline Rojo hierro & $\begin{array}{l}\text { Tarda en secar } \\
\text { menos de } 4 \mathrm{~h}\end{array}$ & $\begin{array}{l}\text { Tarda en secar } \\
\text { entre } 4 \text { y } 8 \mathrm{~h}\end{array}$ & $\begin{array}{l}\text { Tarda en secar } \\
\text { entre } 24 \text { y } 32 \mathrm{~h}\end{array}$ \\
\hline Ocre rojo & $\begin{array}{l}\text { Tarda en secar } \\
\text { menos de } 4 \mathrm{~h}\end{array}$ & $\begin{array}{l}\text { Tarda en secar } \\
\text { entre } 4 \text { y } 8 \mathrm{~h}\end{array}$ & $\begin{array}{l}\text { Tarda en secar } \\
\text { entre } 24 \text { y } 32 \mathrm{~h}\end{array}$ \\
\hline Violeta manganeso & $\begin{array}{c}\text { Tarda en secar } \\
\text { entre } 4 \text { y } 8 \mathrm{~h}\end{array}$ & $\begin{array}{l}\text { Tarda en secar } \\
\text { entre } 16 \text { y } 24 \mathrm{~h}\end{array}$ & $\begin{array}{l}\text { Tarda en secar } \\
\text { entre } 24 \text { y } 32 \mathrm{~h}\end{array}$ \\
\hline Azul cobalto & $\begin{array}{l}\text { Tarda en secar } \\
\text { menos de } 4 \mathrm{~h}\end{array}$ & $\begin{array}{l}\text { Tarda en secar } \\
\text { entre } 4 \text { y } 8 \text { h }\end{array}$ & $\begin{array}{l}\text { Tarda en secar } \\
\text { entre } 72 \text { y } 80 \mathrm{~h}\end{array}$ \\
\hline Azul ultramar & $\begin{array}{c}\text { Tarda en secar } \\
\text { entre } 4 \text { y } 8 \mathrm{~h}\end{array}$ & $\begin{array}{l}\text { Tarda en secar } \\
\text { entre } 8 \text { y } 16 \mathrm{~h}\end{array}$ & $\begin{array}{l}\text { Tarda en secar } \\
\text { entre } 32 \text { y } 40 \mathrm{~h}\end{array}$ \\
\hline Azul Prusia & $\begin{array}{l}\text { Tarda en secar } \\
\text { menos de } 4 \mathrm{~h}\end{array}$ & $\begin{array}{l}\text { Tarda en secar } \\
\text { entre } 64 \text { y } 72 \mathrm{~h}\end{array}$ & $\begin{array}{c}\text { Tarda en secar } \\
\text { entre } 168 \text { y } 176 \mathrm{~h}\end{array}$ \\
\hline Azul ftalocianina & $\begin{array}{r}\text { Tarda en secar } \\
\text { entre } 24 \text { y } 32 \mathrm{~h}\end{array}$ & $\begin{array}{l}\text { Tarda en secar } \\
\text { entre } 72 \text { y } 80 \mathrm{~h}\end{array}$ & $\begin{array}{c}\text { Tarda en secar } \\
\text { entre } 160 \text { y } 168 \mathrm{~h}\end{array}$ \\
\hline Azul cerúleo & $\begin{array}{l}\text { Tarda en secar } \\
\text { menos de } 4 \mathrm{~h}\end{array}$ & $\begin{array}{l}\text { Tarda en secar } \\
\text { entre } 8 \text { y } 16 \text { h }\end{array}$ & $\begin{array}{l}\text { Tarda en secar } \\
\text { entre } 24 \text { y } 32 \mathrm{~h}\end{array}$ \\
\hline Verde óxido cromo & $\begin{array}{l}\text { Tarda en secar } \\
\text { menos de } 4 \mathrm{~h}\end{array}$ & $\begin{array}{l}\text { Tarda en secar } \\
\text { entre } 16 \text { y } 24 \mathrm{~h}\end{array}$ & $\begin{array}{l}\text { Tarda en secar } \\
\text { entre } 32 \text { y } 40 \mathrm{~h}\end{array}$ \\
\hline Verde ftalocianina & $\begin{array}{l}\text { Tarda en secar } \\
\text { entre } 8 \text { y } 16 \mathrm{~h}\end{array}$ & $\begin{array}{r}\text { Tarda en secar } \\
\text { entre } 56 \text { y } 64 \mathrm{~h}\end{array}$ & $\begin{array}{l}\text { Tarda en secar } \\
\text { entre } 112 \text { y } 120 \mathrm{~h}\end{array}$ \\
\hline Siena natural & $\begin{array}{l}\text { Tarda en secar } \\
\text { entre } 4 \text { y } 8 \mathrm{~h}\end{array}$ & $\begin{array}{l}\text { Tarda en secar } \\
\text { entre } 32 \text { y } 40 \mathrm{~h}\end{array}$ & $\begin{array}{l}\text { Tarda en secar } \\
\text { entre } 56 \text { y } 64 \mathrm{~h}\end{array}$ \\
\hline Siena tostada & $\begin{array}{c}\text { Tarda en secar } \\
\text { entre } 4 \text { y } 8 \mathrm{~h}\end{array}$ & $\begin{array}{r}\text { Tarda en secar } \\
\text { entre } 40 \text { y } 48 \mathrm{~h}\end{array}$ & $\begin{array}{l}\text { Tarda en secar } \\
\text { entre } 72 \text { y } 80 \mathrm{~h}\end{array}$ \\
\hline Sombra natural & $\begin{array}{l}\text { Tarda en secar } \\
\text { menos de } 4 \mathrm{~h}\end{array}$ & $\begin{array}{r}\text { Tarda en secar } \\
\text { entre } 40 \text { y } 48 \mathrm{~h}\end{array}$ & $\begin{array}{l}\text { Tarda en secar } \\
\text { entre } 96 \text { y } 104 \mathrm{~h}\end{array}$ \\
\hline Sombra tostada & $\begin{array}{l}\text { Tarda en secar } \\
\text { menos de } 4 \mathrm{~h}\end{array}$ & $\begin{array}{l}\text { Tarda en secar } \\
\text { entre } 40 \text { y } 48 \mathrm{~h}\end{array}$ & $\begin{array}{l}\text { Tarda en secar } \\
\text { entre } 72 \text { y } 80 \mathrm{~h}\end{array}$ \\
\hline Negro marfil & $\begin{array}{l}\text { Tarda en secar } \\
\text { entre } 8 \text { y } 16 \mathrm{~h}\end{array}$ & $\begin{array}{l}\text { Tarda en secar } \\
\text { entre } 16 \text { y } 24 \mathrm{~h}\end{array}$ & $\begin{array}{l}\text { Tarda en secar } \\
\text { entre } 72 \text { y } 80 \mathrm{~h}\end{array}$ \\
\hline Negro hierro & $\begin{array}{l}\text { Tarda en secar } \\
\text { entre } 8 \text { y } 16 \text { h }\end{array}$ & $\begin{array}{l}\text { Tarda en secar } \\
\text { entre } 32 \text { y } 40 \mathrm{~h}\end{array}$ & $\begin{array}{l}\text { Tarda en secar } \\
\text { entre } 96 \text { y } 104 \mathrm{~h}\end{array}$ \\
\hline Negro humo & $\begin{array}{l}\text { Tarda en secar } \\
\text { entre } 8 \text { y } 16 \mathrm{~h}\end{array}$ & $\begin{array}{l}\text { Tarda en secar } \\
\text { entre } 16 \text { y } 24 \mathrm{~h}\end{array}$ & $\begin{array}{l}\text { Tarda en secar } \\
\text { entre } 56 \text { y } 64 \mathrm{~h}\end{array}$ \\
\hline
\end{tabular}




\begin{tabular}{|c|c|c|c|}
\hline \multicolumn{4}{|c|}{$\begin{array}{l}\text { TABLA XII. SECADO DE LOS ÓLEOS ALQUÍDICOS AGLUTINADOS } \\
\text { CON } 25 \% \text { WひN LIQUIN-75\% ACEITE } \\
\text { SOPORTE: TELA DE LINO IMPRIMACIÓN: MEDIA CRETA }\end{array}$} \\
\hline Pigmentos & $\begin{array}{c}\text { CAPA DE PINTURA } \\
\text { DELGADA }\end{array}$ & $\begin{array}{c}\text { CAPA DE PINTURA } \\
\text { EMPASTADA }\end{array}$ & $\begin{array}{c}\text { CAPA DE EMPASTE } \\
\text { GRUESO }\end{array}$ \\
\hline Blanco plomo & $\begin{array}{l}\text { Tarda en secar } \\
\text { entre } 24 \text { y } 32 \mathrm{~h}\end{array}$ & $\begin{array}{l}\text { Tarda en secar } \\
\text { entre } 88 \text { y } 96 \text { h }\end{array}$ & $\begin{array}{c}\text { Tarda en secar } \\
\text { entre } 112 \text { y } 120 \mathrm{~h}\end{array}$ \\
\hline Blanco titanio & $\begin{array}{l}\text { Tarda en secar } \\
\text { entre } 16 \text { y } 24 \mathrm{~h}\end{array}$ & $\begin{array}{r}\text { Tarda en secar } \\
\text { entre } 48 \text { y } 56 \mathrm{~h}\end{array}$ & $\begin{array}{c}\text { Tarda en secar } \\
\text { entre } 120 \text { y } 128 \mathrm{~h}\end{array}$ \\
\hline Blanco zinc & $\begin{array}{l}\text { Tarda en secar } \\
\text { menos de } 4 \mathrm{~h}\end{array}$ & $\begin{array}{l}\text { Tarda en secar } \\
\text { entre } 24 \text { y } 32 \mathrm{~h}\end{array}$ & $\begin{array}{l}\text { Tarda en secar } \\
\text { entre } 56 \text { y } 64 \mathrm{~h}\end{array}$ \\
\hline Amarillo cadmio & $\begin{array}{l}\text { Tarda en secar } \\
\text { menos de } 4 \mathrm{~h}\end{array}$ & $\begin{array}{l}\text { Tarda en secar } \\
\text { entre } 16 \text { y } 24 \mathrm{~h}\end{array}$ & $\begin{array}{l}\text { Tarda en secar } \\
\text { entre } 40 \text { y } 48 \text { h }\end{array}$ \\
\hline Amarillo Hansa & $\begin{array}{l}\text { Tarda en secar } \\
\text { entre } 24 \text { y } 32 \mathrm{~h}\end{array}$ & $\begin{array}{r}\text { Tarda en secar } \\
\text { entre } 72 \text { y } 80 \mathrm{~h}\end{array}$ & $\begin{array}{c}\text { Tarda en secar } \\
\text { entre } 104 \text { y } 112 \mathrm{~h}\end{array}$ \\
\hline Amarillo cromo & $\begin{array}{l}\text { Tarda en secar } \\
\text { entre } 4 \text { y } 8 \mathrm{~h}\end{array}$ & $\begin{array}{l}\text { Tarda en secar } \\
\text { entre } 56 \text { y } 64 \mathrm{~h}\end{array}$ & $\begin{array}{l}\text { Tarda en secar } \\
\text { entre } 96 \text { y } 104 \mathrm{~h}\end{array}$ \\
\hline Amarillo Nápoles & $\begin{array}{l}\text { Tarda en secar } \\
\text { menos de } 4 \mathrm{~h}\end{array}$ & $\begin{array}{l}\text { Tarda en secar } \\
\text { entre } 4 \text { y } 8 \mathrm{~h}\end{array}$ & $\begin{array}{l}\text { Tarda en secar } \\
\text { entre } 16 \text { y } 24 \mathrm{~h}\end{array}$ \\
\hline Ocre amarillo & $\begin{array}{l}\text { Tarda en secar } \\
\text { menos de } 4 \mathrm{~h}\end{array}$ & $\begin{array}{l}\text { Tarda en secar } \\
\text { entre } 72 \text { y } 80 \mathrm{~h}\end{array}$ & $\begin{array}{l}\text { Tarda en secar } \\
\text { entre } 112 \text { y } 120 \mathrm{~h}\end{array}$ \\
\hline Rojo cadmio & $\begin{array}{l}\text { Tarda en secar } \\
\text { entre } 4 \text { y } 8 \mathrm{~h}\end{array}$ & $\begin{array}{l}\text { Tarda en secar } \\
\text { entre } 16 \text { y } 24 \mathrm{~h}\end{array}$ & $\begin{array}{l}\text { Tarda en secar } \\
\text { entre } 40 \text { y } 48 \text { h }\end{array}$ \\
\hline Rojo naftol & $\begin{array}{l}\text { Tarda en secar } \\
\text { entre } 32 \text { y } 40 \mathrm{~h}\end{array}$ & $\begin{array}{c}\text { Tarda en secar } \\
\text { entre } 128 \text { y } 136 \mathrm{~h}\end{array}$ & $\begin{array}{c}\text { Tarda en secar } \\
\text { entre } 152 \text { y } 160 \mathrm{~h}\end{array}$ \\
\hline Carmín alizarina & $\begin{array}{l}\text { Tarda en secar } \\
\text { entre } 16 \text { y } 24 \mathrm{~h}\end{array}$ & $\begin{array}{r}\text { Tarda en secar } \\
\text { entre } 80 \text { y } 88 \mathrm{~h}\end{array}$ & $\begin{array}{c}\text { Tarda en secar } \\
\text { entre } 128 \text { y } 136 \mathrm{~h}\end{array}$ \\
\hline Rojo hierro & $\begin{array}{l}\text { Tarda en secar } \\
\text { menos de } 4 \mathrm{~h}\end{array}$ & $\begin{array}{l}\text { Tarda en secar } \\
\text { entre } 8 \text { y } 16 \mathrm{~h}\end{array}$ & $\begin{array}{l}\text { Tarda en secar } \\
\text { entre } 64 \text { y } 72 \mathrm{~h}\end{array}$ \\
\hline Ocre rojo & $\begin{array}{l}\text { Tarda en secar } \\
\text { entre } 4 \text { y } 8 \mathrm{~h}\end{array}$ & $\begin{array}{l}\text { Tarda en secar } \\
\text { entre } 8 \text { y } 16 \mathrm{~h}\end{array}$ & $\begin{array}{l}\text { Tarda en secar } \\
\text { entre } 48 \text { y } 56 \text { h }\end{array}$ \\
\hline Violeta manganeso & $\begin{array}{l}\text { Tarda en secar } \\
\text { entre } 4 \text { y } 8 \mathrm{~h}\end{array}$ & $\begin{array}{l}\text { Tarda en secar } \\
\text { entre } 16 \text { y } 24 \mathrm{~h}\end{array}$ & $\begin{array}{l}\text { Tarda en secar } \\
\text { entre } 24 \text { y } 32 \text { h }\end{array}$ \\
\hline Azul cobalto & $\begin{array}{l}\text { Tarda en secar } \\
\text { entre } 4 \text { y } 8 \mathrm{~h}\end{array}$ & $\begin{array}{r}\text { Tarda en secar } \\
\text { entre } 32 \text { y } 40 \mathrm{~h}\end{array}$ & $\begin{array}{l}\text { Tarda en secar } \\
\text { entre } 80 \text { y } 88 \text { h }\end{array}$ \\
\hline Azul ultramar & $\begin{array}{l}\text { Tarda en secar } \\
\text { entre } 4 \text { y } 8 \mathrm{~h}\end{array}$ & $\begin{array}{l}\text { Tarda en secar } \\
\text { entre } 16 \text { y } 24 \mathrm{~h}\end{array}$ & $\begin{array}{l}\text { Tarda en secar } \\
\text { entre } 40 \text { y } 48 \mathrm{~h}\end{array}$ \\
\hline Azul Prusia & $\begin{array}{l}\text { Tarda en secar } \\
\text { menos de } 4 \mathrm{~h}\end{array}$ & $\begin{array}{l}\text { Tarda en secar } \\
\text { entre } 64 \text { y } 72 \mathrm{~h}\end{array}$ & $\begin{array}{c}\text { Tarda en secar } \\
\text { entre } 168 \text { y } 176 \mathrm{~h}\end{array}$ \\
\hline Azul ftalocianina & $\begin{array}{l}\text { Tarda en secar } \\
\text { entre } 24 \text { y } 32 \mathrm{~h}\end{array}$ & $\begin{array}{l}\text { Tarda en secar } \\
\text { entre } 80 \text { y } 88 \mathrm{~h}\end{array}$ & $\begin{array}{c}\text { Tarda en secar } \\
\text { entre } 168 \text { y } 176 \mathrm{~h}\end{array}$ \\
\hline Azul cerúleo & $\begin{array}{l}\text { Tarda en secar } \\
\text { menos de } 4 \mathrm{~h}\end{array}$ & $\begin{array}{l}\text { Tarda en secar } \\
\text { entre } 16 \text { y } 24 \mathrm{~h}\end{array}$ & $\begin{array}{l}\text { Tarda en secar } \\
\text { entre } 32 \text { y } 40 \mathrm{~h}\end{array}$ \\
\hline Verde óxido cromo & $\begin{array}{l}\text { Tarda en secar } \\
\text { menos de } 4 \mathrm{~h}\end{array}$ & $\begin{array}{l}\text { Tarda en secar } \\
\text { entre } 16 \text { y } 24 \mathrm{~h}\end{array}$ & $\begin{array}{l}\text { Tarda en secar } \\
\text { entre } 64 \text { y } 72 \mathrm{~h}\end{array}$ \\
\hline Verde ftalocianina & $\begin{array}{l}\text { Tarda en secar } \\
\text { entre } 8 \text { y } 16 \mathrm{~h}\end{array}$ & $\begin{array}{l}\text { Tarda en secar } \\
\text { entre } 64 \text { y } 72 \mathrm{~h}\end{array}$ & $\begin{array}{c}\text { Tarda en secar } \\
\text { entre } 144 \text { y } 152 \mathrm{~h}\end{array}$ \\
\hline
\end{tabular}




\begin{tabular}{|c|c|c|c|}
\hline Siena natural & $\begin{array}{l}\text { Tarda en secar } \\
\text { entre } 8 \text { y } 16 \mathrm{~h}\end{array}$ & $\begin{array}{l}\text { Tarda en secar } \\
\text { entre } 40 \text { y } 48 \mathrm{~h}\end{array}$ & $\begin{array}{l}\text { Tarda en secar } \\
\text { entre } 80 \text { y } 88 \mathrm{~h}\end{array}$ \\
\hline Siena tostada & $\begin{array}{l}\text { Tarda en secar } \\
\text { entre } 8 \text { y } 16 \mathrm{~h}\end{array}$ & $\begin{array}{l}\text { Tarda en secar } \\
\text { entre } 48 \text { y } 56 \text { h }\end{array}$ & $\begin{array}{l}\text { Tarda en secar } \\
\text { entre } 96 \text { y } 104 \mathrm{~h}\end{array}$ \\
\hline Sombra natural & $\begin{array}{l}\text { Tarda en secar } \\
\text { menos de } 4 \mathrm{~h}\end{array}$ & $\begin{array}{l}\text { Tarda en secar } \\
\text { entre } 40 \text { y } 48 \mathrm{~h}\end{array}$ & $\begin{array}{l}\text { Tarda en secar } \\
\text { entre } 104 \text { y } 112 \mathrm{~h}\end{array}$ \\
\hline Sombra tostada & $\begin{array}{l}\text { Tarda en secar } \\
\text { menos de } 4 \mathrm{~h}\end{array}$ & $\begin{array}{l}\text { Tarda en secar } \\
\text { entre } 40 \text { y } 48 \mathrm{~h}\end{array}$ & $\begin{array}{l}\text { Tarda en secar } \\
\text { entre } 72 \text { y } 80 \mathrm{~h}\end{array}$ \\
\hline Negro marfil & $\begin{array}{l}\text { Tarda en secar } \\
\text { entre } 16 \text { y } 24 \mathrm{~h}\end{array}$ & $\begin{array}{l}\text { Tarda en secar } \\
\text { entre } 32 \text { y } 40 \mathrm{~h}\end{array}$ & $\begin{array}{l}\text { Tarda en secar } \\
\text { entre } 72 \text { y } 80 \mathrm{~h}\end{array}$ \\
\hline Negro hierro & $\begin{array}{l}\text { Tarda en secar } \\
\text { entre } 16 \text { y } 24 \mathrm{~h}\end{array}$ & $\begin{array}{r}\text { Tarda en secar } \\
\text { entre } 48 \text { y } 56 \mathrm{~h}\end{array}$ & $\begin{array}{l}\text { Tarda en secar } \\
\text { entre } 96 \text { y } 104 \mathrm{~h}\end{array}$ \\
\hline Negro humo & $\begin{array}{l}\text { Tarda en secar } \\
\text { entre } 8 \text { y } 16 \mathrm{~h}\end{array}$ & $\begin{array}{l}\text { Tarda en secar } \\
\text { entre } 24 \text { y } 32 \mathrm{~h}\end{array}$ & $\begin{array}{l}\text { Tarda en secar } \\
\text { entre } 56 \text { y } 64 \mathrm{~h}\end{array}$ \\
\hline
\end{tabular}

\subsection{Craquelados en las pinturas aglutinadas con 25\% Liquin-75\% aCeite DE LINAZA}

Para comprobar la flexibilidad de estas pinturas se ha esperado a que sequen para ver si se han craquelado durante el secado, o si lo hacen al someterlas a una fuerte tensión mecánica doblando la tela.

a) Grietas: después de dejar secar las pinturas durante un año, se ha podido constatar que no se ha generado ninguna grieta espontánea, ni en la capa fina ni en la capa de empaste, ni tampoco en la capa de empaste grueso.

b) Rajas: aquí es donde sí surgen problemas, puesto que estas pinturas tienen una resistencia muy limitada a las tensiones mecánicas que puedan ser ejercidas sobre ellas. Las capas finas son bastante flexibles, pero si se ejerce la suficiente presión acaban apareciendo rajas en forma de espiga (fig. 17). Los empastes son más frágiles, y craquelan en cuanto se dobla un poco la tela, produciendo también rajas en forma de espiga (fig. 18).

De todos modos, aunque todos los empastes pueden craquelar por acciones mecánicas externas, no todos los colores tienen el mismo grado de flexibilidad (o carencia de ella). Hay colores como el amarillo Hansa, ocre amarillo, rojo naftol, carmín de alizarina, azul Prusia, azul ftalo, verde ftalo, siena natural, siena tostada, sombra natural, sombra tostada y negro de hierro que han secado en forma de una goma dura, bastante similar a como seca la pintura al óleo. El resto han secado de una forma más similar a la de una argamasa quebradiza en los empastes.

En este sentido el resultado ha sido inferior al de los óleos alquídicos $W \mathcal{E} N$ Griffin. Pero conviene insistir de nuevo en que, de manera análoga, los resultados de flexibilidad de los óleos tradicionales autoproducidos también son inferiores a los de los óleos industriales. 


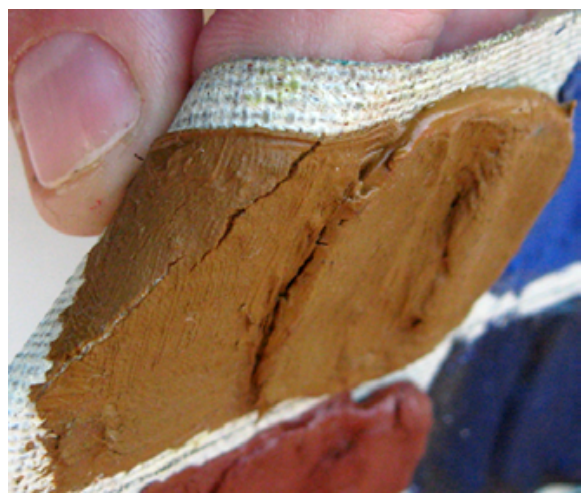

Fig. 17. Si se flexiona fuertemente la tela, la capa fina de pintura craquela.

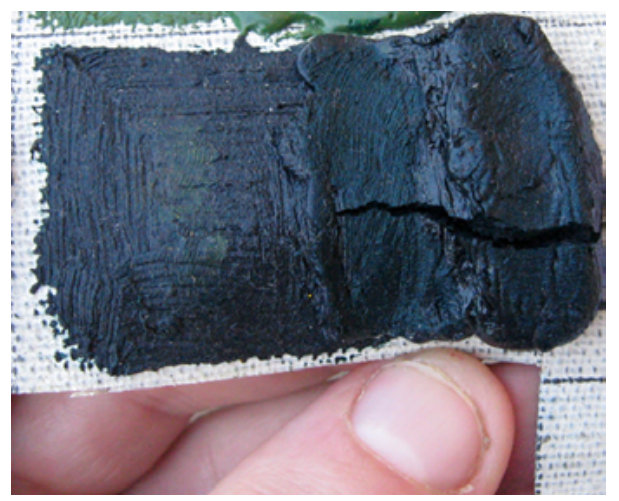

Fig. 18. Los empastes son más frágiles que la capa fina.

\section{CONCLUSIONES}

La principal conclusión de la primera parte de la investigación, tras numerosos experimentos, análisis técnicos de laboratorio y pruebas prácticas pictóricas, es que el mejor aglutinante para autoproducir óleos alquídicos similares a los Griffin de Winsor \& Newton es una mezcla de 25\% W\&N Liquin y 75\% aceite de linaza. Los óleos alquídicos We̛ $N$ Griffin, más que unas pinturas alquídicas convencionales al estilo de los esmaltes para el hogar, son unos óleos modificados con resina alquídica, de ahí que el componente proporcionalmente mayoritario de su aglutinante sea el aceite de linaza.

Con respecto a las pinturas autoproducidas con dicho aglutinante, las conclusiones que se pueden extraer en las diversas variables estudiadas son las siguientes:

Cuerpo y viscosidad: en general han obtenido buenos resultados en esta variable. Como se puede observar en la tabla viII, de la muestra de 28 colores estudiados, 18 han conseguido un cuerpo cremoso óptimo e igual al de sus contrapartidas de We $N$ Griffin. Otros 4 han quedado a medio camino entre cremosos y poco viscosos, lo que los hace inferiores en esta variable pero todavía válidos. Y los 6 restantes han quedado 5 poco viscosos y 1 semilíquido. Son estos seis (ocre rojo, azul cerúleo, verde óxido de cromo, rojo hierro, amarillo Nápoles y sobre todo amarillo de cromo) los que son menos recomendables; y de hecho W\& $N$ Griffin no incluye en su gama los tres últimos.

Textura y empaste: los colores que quedan cremosos al autoproducirlos (ver tabla viII) permiten realizar unas texturas y unos empastes de una plasticidad casi idéntica a los de los W\& $N$ Griffin. El resto permiten crear empastes, pero su capacidad para crear texturas es muy inferior.

Brillo: todos tienen un brillo muy similar al de los WeN Griffin. 
Flexibilidad: es la única variable en la que se muestran sistemáticamente inferiores a la referencia $W \mho N N$ Griffin. No presentan craquelados espontáneos, pero tienden a agrietarse cuando se ejerce una fuerte tensión mecánica sobre la película seca, especialmente en los empastes. Los pigmentos de granulometría menor y las tierras han conseguido unos óleos alquídicos autoproducidos algo más flexibles que el resto de pigmentos. Pero, con todo, la principal conclusión que se puede extraer de su menor flexibilidad es que conviene trabajar con estas pinturas sobre soportes rígidos, especialmente si se pinta con empastes gruesos, los cuales, en cualquier caso, no son muy recomendables. Separación de aglutinante y pigmento: en general tienen una estabilidad bastante similar a la de los W\&N Griffin. De los veintiocho colores estudiados (tabla Ix), 18 han conseguido un resultado óptimo, 5 han manifestado una pequeña separación del aglutinante y otros 5 han mostrado una importante separación de aglutinante y pigmento. Estos cinco últimos (blanco de plomo, amarillo Nápoles, rojo cadmio, violeta manganeso y azul cerúleo) son los únicos que no han estado a la altura y conviene fabricarlos únicamente cuando vayan a ser utilizados; y no almacenarlos en tubos de aluminio durante largos períodos de tiempo.

Margen de secado: son claramente superiores a los WeN Griffin. Se puede pintar con ellos durante más tiempo antes de que se sequen en la paleta (entre 48 y $96 \mathrm{~h}$ ).

Secado: manejan unos tiempos de secado similares a los del modelo de referencia. Pero como puede observarse en la tabla x son mayoría los colores que secan algo más rápido que sus contrapartidas WéN Griffin. Por lo que la conclusión es que en esta variable son algo superiores al modelo de referencia.

Conviene recordar que la característica más importante de los óleos alquídicos autoproducidos tiene que ser su rapidez de secado. Y los aglutinados con $25 \%$ We $N$ Liquin-75\% aceite de linaza son unas pinturas que secan incluso un poco más rápido que los We̛ $N$ Griffin sobre el soporte pictórico, pero más despacio sobre la paleta (soporte no poroso), lo que es ideal para el artista pintor.

La tabla XIII es una gráfica que resume, de forma muy fácil de entender, una comparativa entre las cualidades de los óleos alquídicos autoproducidos aglutinados con 25\% Wer $N$ Liquin-75\% aceite de linaza y las de los óleos alquídicos $W \mho N$ Griffin. Y lo hace a través de las variables estudiadas.

En líneas generales sus cualidades son prácticamente iguales a las del modelo de referencia $W \& N$ Griffin. Ciertamente en alguna variable se han mostrado algo mejores (secado, margen de secado) y en alguna un poco inferiores (flexibilidad). En otras se han mostrado muy similares, aunque no en todos los pigmentos (cuerpo y viscosidad, textura y empaste, separación de aglutinante y pigmento); por eso están entre iguales y peores que W\&N Griffin. Y es por ello por lo que algunos pigmentos han demostrado ser más adecuados que otros para la autoproducción de óleos alquídicos.

Finalmente, la tabla XIv puede ser muy útil para el pintor, puesto que clasifica los pigmentos de la muestra precisamente según su mayor o menor idoneidad para producir óleos alquídicos, haciendo un ejercicio de síntesis de los datos reco- 


\begin{tabular}{|c|c|c|}
\hline \multicolumn{3}{|c|}{$\begin{array}{l}\text { TABLA XIII. VARIABLES DE LOS ÓLEOS ALQUÍDICOS AGLUTINADOS } \\
\text { CON } 25 \% W \& N \text { LIQUIN-75\% ACEITE LINAZA }\end{array}$} \\
\hline MEJORES QUE W\& $N$ GRIFFIN & IgUALES QUe W\&N GRIFFIN & Peores que WひN GRIFFIN \\
\hline \multirow{2}{*}{$\begin{array}{l}\text { Secado } \\
\text { Margen de secado }\end{array}$} & Brillo & Flexibilidad \\
\hline & \multicolumn{2}{|c|}{$\begin{array}{c}\text { Cuerpo y viscosidad } \\
\text { Textura y empaste } \\
\text { Separación aglutinante-pigmento }\end{array}$} \\
\hline
\end{tabular}

\begin{tabular}{lll}
\hline \multicolumn{3}{c}{ TABLA XIV. CLASIFICACIÓN DE LOS PIGMENTOS SEGÚN SU IDONEIDAD } \\
\multicolumn{1}{c}{ PARA LA PRODUCCIÓN DE ÓLEOS ALQUÍDICOS } \\
\hline \multicolumn{1}{c}{ Pigmentos óptimos } & \multicolumn{1}{c}{ PIgmentos ReComendables } & PIgmentos No ReCOMENDABLes \\
\hline Amarillo Hansa & Blanco de plomo & Amarillo cromo \\
Ocre amarillo & Blanco titanio & Amarillo Nápoles \\
Rojo naftol & Blanco de zinc & Rojo de hierro \\
Carmín de alizarina & Amarillo cadmio & Ocre rojo \\
Azul de Prusia & Rojo cadmio & Azul cerúleo \\
Azul ftalocianina & Violeta manganeso & Verde óxido de cromo \\
Verde ftalocianina & Azul cobalto & \\
Siena natural & Azul ultramar & \\
Siena tostada & & \\
Sombra natural & & \\
Sombra tostada & & \\
Negro marfil & & \\
Negro hierro & & \\
Negro humo & & \\
\hline
\end{tabular}

gidos en todas las variables. De hecho le será de gran ayuda al artista para seleccionar su paleta de colores y para evitar desperdiciar tiempo, dinero y trabajo con los pigmentos menos recomendables para esta técnica pictórica.

Los pigmentos óptimos son aquellos que, cuando se aglutinan con la mezcla $25 \% W \mho N$ Liquin-75\% aceite de linaza, quedan exactamente igual que los óleos alquídicos $W \mho N$ Griffin. Los pigmentos recomendables son aquellos inferiores en alguna variable, pero sin que ello suponga un obstáculo real para la práctica pictórica o los diferencie demasiado del modelo de referencia (amarilleo en los blancos, separación de aglutiante y pigmento en el rojo cadmio y violeta manganeso, etc.). Y, por último, los pigmentos no recomendables son los que no consiguen siquiera un aspecto similar a los WéN Griffin principalmente debido a su falta de cuerpo y viscosidad y textura y empaste. 


\section{BIBLIOGRAFÍA}

Doerner, Max. Los materiales de pintura y su empleo en el arte. Barcelona: Reverté, 2001.

Espinosa, Mariano. Tesis doctoral Las resinas alquidicas aplicadas a la pintura artística. Barcelona: Universitat de Barcelona: Departament de pintura. Barcelona, 2010.

Espinosa, Mariano. «Los óleos alquídicos Griffin: composición, propiedades y aplicación». Revista de Bellas Artes 11. (2013): 127-157. https://riull.ull.es/xmlui/bitstream/handle/915/2410/ BA_11_\%282013\%29_06.pdf?sequence=5\&isAllowed=y.

Espinosa, Mariano. «Los alquídicos en la pintura contemporánea». Revista de Bellas Artes 13. (2016): 183-212. https://riull.ull.es/xmlui/bitstream/handle/915/6440/BA_13_\%28201516\%29_09.pdf?sequence $=1 \&$ isAllowed=y.

Meklenburg, Marion. «Determining the aceptable ranges of relative humidity and temperatura in Museums and Galleries. Part 2, Structural Response to Temperature». Smithsonian Museum Conservation Institute (2007). http://www.si.edu/mci/downloads/reports/Mecklenburg-Part2-Temp.pdf. (consultado el 21-3-2009).

Mayer, Ralph. Materiales y técnicas del arte. Madrid: H Blume Ediciones, 1993

Pedrola, Antoni. Materiales y procedimientos pictóricos. Barcelona: Ariel, 1998.

Ploeger, Rebecca, Scalarone, Dominique y Chiantore, Oscar. «Characterization of commercial artists' alkyd paints». Journal of Cultural Heritage 9. (2008): 412-419. 